\title{
Phenylpropanoid Substituted Flavan-3-ols from Trichilia catigua and their In Vitro Antioxidative Activity
}

\author{
Flávia O. Resende, ${ }^{a}$ Edson Rodrigues-Filho, ${ }^{b}$ Heinrich Luftmann, ${ }^{c}$ \\ Frank Petereit ${ }^{d}$ and João C. Palazzo de Mello ${ }^{* a}$
}

\author{
aPrograma de Pós-Graduação em Ciências Farmacêuticas, Universidade Estadual de Maringá, \\ Av. Colombo No. 5790, 87020-900 Maringá-PR, Brazil \\ ${ }^{b}$ Departamento de Química, Universidade Federal de São Carlos, \\ Rod. Washington Luiz, $\mathrm{km}$ 235, 13905-905 São Carlos-SP, Brazil \\ 'Organisch-Chemisches Institut, Universität Münster, Corrensstrasse 40, \\ D-48149, Münster, Germany \\ ${ }^{d}$ Institut für Pharmazeutische Biologie und Phytochemie, Universität Münster, \\ Hittorfstrasse 56, D-48149, Münster, Germany
}

\begin{abstract}
O novo flavan-3-ol contendo um substituinte fenilpropanoide apocinina E, juntamente com oito substâncias conhecidas, epicatequina, procianidina B2, procianidina B4, procianidina $\mathrm{C} 1$, cinchonaína $\mathrm{Ia}$, cinchonaína $\mathrm{Ib}$, cinchonaína IIb e cinchonaína IIa foram isoladas a partir do extrato acetona- $\mathrm{H}_{2} \mathrm{O}$ das cascas secas de Trichilia catigua. As substâncias cinchonaína Ib e cinchonaína IIb foram reavaliadas em relação à sua estereoquímica. Todas as substâncias foram caracterizadas por análises espectroscópicas incluindo ressonância magnética nuclear (NMR) 1D e 2D e espectrometria de massa (MS) de seus derivados acetilados. A configuração absoluta do substituinte fenilpropanoide foi determinada por espectropolarimetria de dicroísmo circular (CD) e pela análise do efeito anisotrópico empregando modelo de Dreiding, e por experimento de espectroscopia de efeito nuclear Overhauser (NOESY NMR). As nove substâncias mostraram maior atividade sobre o sequestro de radical livre e poder de redução do que o ácido ascórbico e Trolox frente ao radical livre 2,2-difenil-1-picrilhidrazila e no sistema do teste de redução do ferro $\left(\mathrm{Fe}^{3+}-\mathrm{Fe}^{2+}\right)$.
\end{abstract}

The new phenylpropanoid substituted flavan-3-ol apocynin E, together with eight known compounds, epicatechin, procyanidin $\mathrm{B} 2$, procyanidin $\mathrm{B} 4$, procyanidin $\mathrm{C} 1$, cinchonain Ia, cinchonain $\mathrm{Ib}$, cinchonain $\mathrm{IIb}$, and cinchonain IIa were isolated from an acetone- $\mathrm{H}_{2} \mathrm{O}$ extract of the air-dried stem bark of Trichilia catigua. The cinchonain Ia e Ib were reevaluated to its estereochemistry. All the compounds were characterized by spectroscopic analysis including 1D and 2D nuclear magnetic resonance (NMR) and mass spectrometry (MS) of their peracetate derivatives. The absolute configuration of the phenylpropanoid moiety was determined by circular dichroism (CD) spectra and by analyzing the anisotropic effects in the Dreiding model and nuclear Overhauser effect (NOESY NMR) experiments. The nine isolated compounds showed higher radical scavenging activity and reducing power than ascorbic acid and Trolox in the free-radical 2,2-diphenyl-1-picrylhydrazyl and $\mathrm{Fe}^{3+}-\mathrm{Fe}^{2+}$ reduction assay systems.

Keywords: Trichilia catigua, Meliaceae, cinchonains, proanthocyanidins, antioxidative activity

\section{Introduction}

Trichilia catigua A. Juss. (Meliaceae), commonly known as "catuaba", is a plant native to South and

*e-mail: mello@uem.br
Central America and widely distributed in Brazil. ${ }^{1}$ However, the identity of the plant source is often uncertain, and stem barks from several different species of Erythroxylum or Anemopaegma, all regionally known as "catuaba", are sold commercially. Marques² described the differences among the species known as "catuaba" and 
determined that $T$. catigua is the main species that is sold as "catuaba" in Brazil. The same conclusion was reached by Kletter et al. ${ }^{3}$ and Daolio et al. ${ }^{4}$ The bark of T. catigua has been traditionally used as a health and mental tonic, and especially as a sexual stimulant. ${ }^{3,5}$ Some pharmacological studies of this bark have reported antimicrobial, trypanocidal, antinociceptive, vasorelaxant or dopamine-mediated antidepressantlike effects. ${ }^{5-10}$ The bark contains a high concentration of polyphenols (6.96 $\pm 0.11 \%$; RSD $1.57 \%)$ including flavan-3-ols and phenylpropanoid derivatives, ${ }^{5,11}$ as well as tropane alkaloids. ${ }^{3}$ Other species, T. claussenii and T. lepidota, were evaluated and yielded sesquiterpenoids. ${ }^{12}$ We further investigated the constituents of T. catigua bark and isolated nine polyphenolic constituents, including one new compound. The isolated polyphenols showed high radical scavenging and antioxidative activity in DPPH (2,2-diphenyl-1-picryl-hydrazyl) and $\mathrm{Fe}^{3+}-\mathrm{Fe}^{2+}$ assays.

\section{Results and Discussion}

\section{Isolation of polyphenols from bark of Trichilia catigua}

Multiple chromatography on Sigma-Sephadex ${ }^{\circledR}$ LH-20 and high-speed countercurrent chromatography (HSCCC) of the ethyl acetate fraction originating from an acetone $/ \mathrm{H}_{2} \mathrm{O}(7: 3)$ extract of the air-dried stem bark of T. catigua yielded eight known compounds together with a new compound. The known compounds were identified as epicatechin (1), procyanidin B2 [epicatechin- $(4 \beta \rightarrow 8)$-epicatechin] (2), procyanidin B4 [catechin- $(4 \alpha \rightarrow 8)$-epicatechin] (3), procyanidin C1 [epicatechin- $(4 \beta \rightarrow 8)$-epicatechin- $(4 \beta \rightarrow 8)$-epicatechin] (4), cinchonain Ia (5), cinchonain Ib (6), cinchonain IIb (8), and cinchonain IIa (9) by comparison of the physical and spectral data $\left[{ }^{1} \mathrm{H}\right.$ nuclear magnetic resonance (NMR), ${ }^{1} \mathrm{H}-{ }^{1} \mathrm{H}$ correlation spectroscopy (COSY NMR), $[\alpha]_{\mathrm{D}}^{20}$, mass spectrometry (MS), circular dichroism (CD)] of their peracetates with published data., ${ }^{513-18}$ The new compound was isolated as its peracetate 7a and identified as apocynin E (7).

\section{Structure of phenylpropanoid substituted flavan-3-ols}

Cinchonain Ia (5) and Ib (6) were first described by Nonaka and Nishioka ${ }^{13}$ and their structures were revised by Chen et al., ${ }^{15}$ based on nuclear Overhauser spectroscopy (NOESY NMR), nuclear Overhauser effect (NOE) and CD data. Several reports have been published with ambiguous stereochemistry of both compounds..$^{5,11,16,19,20}$ The now generally accepted structures for cinchonanin Ia and $\mathrm{Ib}$ are outlined in Figure 1.
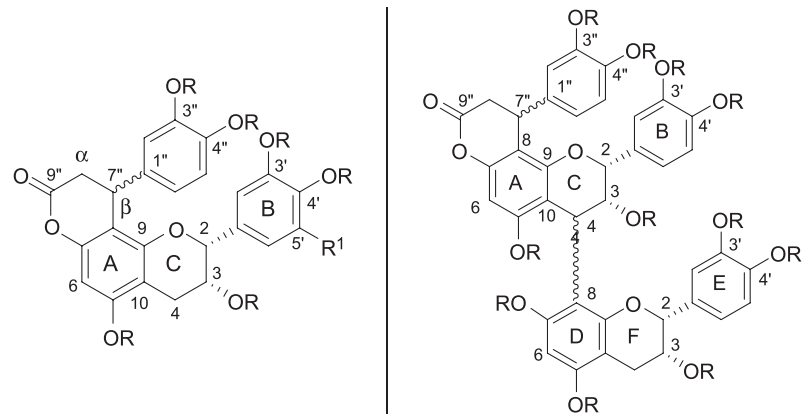

\begin{tabular}{|c|c|c|c|}
\hline & $\mathrm{C}-7 " \rightarrow \mathrm{C}-1 "$ & $\mathrm{R}$ & $\mathrm{R}^{1}$ \\
\hline 5 & $\longrightarrow$ & $\mathrm{H}$ & $\mathrm{H}$ \\
\hline $5 a$ & - & $A c$ & $\mathrm{H}$ \\
\hline 6 & …1.1,11 & $\mathrm{H}$ & $\mathrm{H}$ \\
\hline $6 a$ & …‥111 & Ac & $\mathrm{H}$ \\
\hline 7 & …....111 & $\mathrm{H}$ & $\mathrm{OH}$ \\
\hline $7 a$ & …..1.11 & Ac & OAC \\
\hline
\end{tabular}

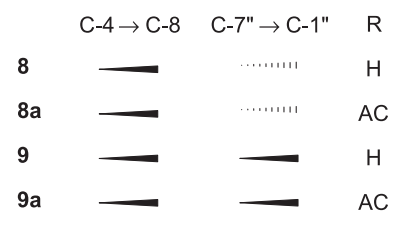

Figure 1. Structures of the compounds isolated from T. catigua.

Compounds $5 \mathbf{a}$ and $6 \mathbf{a}$ showed the same $[\mathrm{M}-\mathrm{H}]^{-}$signal at $m / z 451.4$ in negative ESI-MS (electrospray ionization mass spectrometry). The presence of a basic flavan-3-ol skeleton in each molecule was readily confirmed by the observation of $\mathrm{AMX}_{2}$-type resonances at $\delta 5.20$ (brs) and $5.43(\mathrm{~m}), 5.46$ (brs) and $5.46(\mathrm{~m})$, and between 2.72 and $3.08(\mathrm{~m}, 2 \mathrm{H})$, respectively ascribable to $\mathrm{H}-2, \mathrm{H}-3$ and $\mathrm{H}-4$, for peracetates $\mathbf{5} \mathbf{a}$ and $\mathbf{6 a}$. The appearance of an aromatic proton singlet at $\delta 6.50$ for $\mathbf{5 a}$ and $\delta 6.63$ for $\mathbf{6 a}$ indicated the occurrence of a C8 or C6 attached linkage in the flavan A-ring, while the aromatic $\mathrm{ABX}$-type resonances at $\delta 7.11$ 7.33 , and the chemical shifts and coupling constants were in good agreement with those of the epicatechin peracetate (1a) (Table 1). ${ }^{13} \mathrm{C}$ NMR spectra revealed the presence of a carbonyl ( $\delta 167.3$ and 167.1), a $\beta$-methine carbon ( $\delta 35.1$ and 34.9), a $\alpha$-methylene ( $\delta 36.8$ and 36.5 ) and an additional 1,3,4-trisubstituted aromatic ring system for $\mathbf{5 a}$ and $\mathbf{6 a}$, respectively. This suggests the presence of a phenylpropanoid linked to the A-ring of the epicatechin unit through a carbon-carbon linkage. According to Nonaka and Nishioka ${ }^{13}$ and Tang et al. ${ }^{21}$ the C-8 resonance ( $\delta 111.5$ for $\mathbf{5 a}$ and $\delta 111.1$ for $\mathbf{6 a}$ ) relative to the C-6 $(\delta 104.8$ for $\mathbf{5 a}$ and $\delta 104.5$ for $\mathbf{6 a}$ ) demonstrates the occurrence of a carbon-carbon linkage at the $\mathrm{C}-8$ position for both compounds. The HMBC (heteronuclear multiplebond correlation spectroscopy) spectra of $\mathbf{5} \mathbf{a}$ and $\mathbf{6} \mathbf{a}$ clearly indicated a strong correlation between $\mathrm{H}-7$ "' and C-8 and C-9, H-8" and C-8, C-9" and C-1", and H-6 and C-5, C-7, C-8, and C-10, which would be impossible if the substituent were attached at the $\mathrm{C}-6$ position, and therefore confirmed the position of the phenylpropanoid moiety at C-8.

For compounds $\mathbf{5 a}$ and $\mathbf{6 a}$, the $S$ - or $R$-absolute configuration of the $\beta$-methine carbon in the phenylpropanoid 
Table 1. ${ }^{1} \mathrm{H}$ NMR spectral data of the peracetate compounds $\mathbf{1 a}, \mathbf{5 a}, \mathbf{6 a}$ and $\mathbf{7 a}\left(300 \mathrm{MHz}\right.$, acetone- $\left.d_{6}\right)$

\begin{tabular}{|c|c|c|c|c|}
\hline $\mathrm{H}$ & $\mathbf{1 a}\left(\delta_{\mathrm{H}}\right)(J / \mathrm{Hz})$ & $\mathbf{5 a}\left(\delta_{\mathrm{H}}\right)(J / \mathrm{Hz})$ & $\mathbf{6 a}\left(\delta_{\mathrm{H}}\right)(J / \mathrm{Hz})$ & $7 \mathbf{a}\left(\delta_{\mathrm{H}}\right)(\mathrm{J} / \mathrm{Hz})$ \\
\hline 2 & 5.39, brs & 5.20 , brs & 5.46 , brs & 5.48, brs \\
\hline 3 & $5.52, \mathrm{~m}$ & $5.43, \mathrm{~m}$ & $5.46, \mathrm{~m}$ & $5.45, \mathrm{~m}$ \\
\hline \multirow[t]{2}{*}{4} & 2.84, dd $(1.5,17.7)$ & $2.72, \mathrm{dd}(1.5,16.2)$ & $2.88, \mathrm{dd}(1.8,16.8)$ & $3.01, \mathrm{~m}$ \\
\hline & 3.09, dd $(4.5,17.7)$ & 2.99, dd $(4.5,16.2)$ & 3.08, dd $(4.5,17.7)$ & \\
\hline 6 & $6.60, \mathrm{~d}(2.1)$ & $6.50, \mathrm{~s}$ & $6.63, \mathrm{~s}$ & $6.63, \mathrm{~s}$ \\
\hline 8 & $6.68, \mathrm{~d}(2.1)$ & & & \\
\hline 2 & $7.43, \mathrm{~d}(1.8)$ & $7.33, \mathrm{~d}(1.8)$ & $7.03, \mathrm{~d}(1.8)$ & $7.01, \mathrm{~s}$ \\
\hline 5 & $7.26, \mathrm{~d}(9.0)$ & $7.11, \mathrm{~d}(8.4)$ & $7.14, \mathrm{~d}(5.4)$ & \\
\hline 6 & 7.42, dd $(1.8,9.0)$ & 7.25, dd $(1.8,8.4)$ & $7.17, \mathrm{~m}$ & $7.01, \mathrm{~s}$ \\
\hline $2 "$ & & $6.93, \mathrm{~d}(2.4)$ & $7.14, \mathrm{~d}(1.8)$ & $7.35, \mathrm{~d}(2.1)$ \\
\hline $5 "$ & & $6.90, \mathrm{~d}(8.1)$ & $7.04, \mathrm{~d}(8.4)$ & $7.25, \mathrm{~d}(8.4)$ \\
\hline $6 "$ & & 6.98, dd $(2.4,8.1)$ & 7.25, dd $(1.8,8.4)$ & 7.18 , dd $(2.1,8.4)$ \\
\hline $7^{\prime \prime}$ & & 4.75, brd $(6.0)$ & 4.78, brd $(6.0)$ & 4.80, brd (4.8) \\
\hline \multirow[t]{2}{*}{$8 "$} & & 3.24, dd $(7.5,16.2)$ & 3.34, dd $(7.5,16.2)$ & 3.34 , dd $(7.5,16.2)$ \\
\hline & & 2.90, dd $(1.8,16.2)$ & 3.11, dd $(1.8,16.2)$ & 3.13 , dd $(1.8,16.2)$ \\
\hline
\end{tabular}

substituent was determined based on ${ }^{1} \mathrm{H}$ NMR, 1D- or 2D-NOESY NMR experiments and CD data. The NMR spectrum of 5a revealed resonances due to the $\mathrm{H}-2$ and the ABX-type B-ring in accordance with those of epicatechin (see Experimental part). On the other hand, in acetone- $d_{6}$, 6a displays the $\mathrm{H}-2$ resonance at $\delta 5.46$ and the B-ring proton resonances at $\delta 7.03\left(\mathrm{~d}, J 1.8 \mathrm{~Hz}, \mathrm{H}-2^{\prime}\right), \delta 7.14(\mathrm{~d}$, $J 5.4 \mathrm{~Hz}, \mathrm{H}-5^{\prime}$ ) and $\delta 7.17$ (m, H-6'). The H-2 resonance is shifted downfield, while H-2' and H-6' are shifted upfield compared with those of epicatechin (Table 1). This implies that these protons are anisotropically affected by the aromatic ring in the phenylpropanoid moiety. ${ }^{13}$ Examination of the Dreiding model indicated that in the case of the $\beta$-configuration of the methine proton ( $\left.\mathrm{H}-\mathrm{7}^{\prime \prime}\right)$, the direction of the B-ring to the aromatic ring of the phenylpropanoid moiety leads to the concentration of the electronic cloud, thus causing a shielding effect at the B-ring protons and an opposite effect at H-2. These effects explain the upfield shift of the B-ring proton resonances and the downfield shift of the $\mathrm{H}-2$ resonance in compound 6a. $\mathrm{CD}$ data for 5a show strong negative Cotton effects at 234 and $280 \mathrm{~nm}$ and a positive effect at $255 \mathrm{~nm}$, whereas $\mathbf{6 a}$ exhibited Cotton effects of opposite signs, indicating that these Cotton effects are mainly affected by the configuration at the $\beta$-methine carbon, and are largely unaffected by the asymmetrical flavan C-2 and C-3 atoms; and hence that the absolute configuration at the $\beta$-methine carbon in 5a is $S$ and in 6a is $R$. From the 2D-NOESY NMR experiments, a small effect between the H-7"' and the H-2' and H-6' of the B-ring was observed for compound $\mathbf{5 a}$. Another important observation is the cross peak between
H-2(C) and H-2" and H-6". This could only be the case if the proton 7" in 5a is in $\alpha$-orientation. The compound $\mathbf{6 a}$ with a $\beta$-orientation shows in the NOESY NMR spectrum a strong cross peak between H-7" and the H-2' and H-6' of the B-ring, and H-2" and H-6" of the phenylpropanoid moiety. No effect between H-2(C) and H-2" or H-6" was observed. This situation was confirmed with a Dreiding model, and established compound $\mathbf{5}$ as cinchonain Ia and compound $\mathbf{6}$ as cinchonain Ib.

Compound 7a showed the $[\mathrm{M}+\mathrm{Na}]^{+}$signal at $\mathrm{m} / \mathrm{z} 785.4$ in the positive ESI-MS. The HR-ESI-MS (positive-ion mode) exhibited a pseudo-molecular ion peak at $\mathrm{m} / z .785 .1688[\mathrm{M}+\mathrm{Na}]^{+}$(calcd. for 785.6561). The ${ }^{1} \mathrm{H}$ and ${ }^{13} \mathrm{C}$ NMR data are almost similar to those of cinchonain $\mathrm{Ib}(\mathbf{6 a})$, with the exception of a two-proton singlet corresponding to the 1,3,4,5-substituted B-ring, and proved that compound 7a contained an epigallocatechin unit. This was also confirmed by the ${ }^{1} \mathrm{H}-{ }^{1} \mathrm{H}$ COSY and HMBC spectra. The $R$ absolute configuration of the $\beta$-methine carbon of $\mathbf{7 a}$ was determined by comparing the ${ }^{1} \mathrm{H}$ NMR, NOESY NMR and CD data with those of 5a and 6a. The H-2 and H-3 resonances of 7a suggested that the $\beta$-methine carbon configuration is the same as 6a. The Cotton effect in the CD spectrum of $\mathbf{7 a}$ is in perfect agreement with those found for $\mathbf{6 a}$. Furthermore, the NOESY NMR spectrum shows no effect between the aromatic ring systems, and $\mathrm{H}-2$ ' and $\mathrm{H}-7$ ', confirming the absolute configuration as $R$. Thus, it was concluded that the structure of compound $\mathbf{7}$ corresponds to apocynin E. To the best of our knowledge, $\mathbf{7}$ has been isolated for the first time from a natural source. 
Structure of phenylpropanoid substituted dimeric flavan3-ols

Compounds 8 and 9 were shown to be proanthocyanidin dimers substituted by a phenylpropanoid moiety at the A-ring. Both substances showed the same $[\mathrm{M}-\mathrm{H}]^{-}$peak at $m / z 739.4$ in negative ESI-MS. Compound 9a exhibited a pseudo-molecular ion peak at $\mathrm{m} / \mathrm{z} 619.1785$ [(calcd. for $\left.\mathrm{C}_{61} \mathrm{H}_{54} \mathrm{O}_{26}+2 \mathrm{NH}_{4}\right)^{2+}$ 619.1789] in the HR-ESI-MS (positive-ion mode), ascribable to molecular formula $\mathrm{C}_{61} \mathrm{H}_{54} \mathrm{O}_{26}$, and showed a peak at $m / z$, $1220.4\left[\mathrm{M}+\mathrm{NH}_{4}\right]^{+}$ at ESI-MS. The occurrence of two constituent flavan3-ol units with 2,3-cis configuration in $\mathbf{8 a}$ and $\mathbf{9 a}$ and a phenylpropanoid moiety was deduced from the small coupling constants $\left(J_{2,3}<2 \mathrm{~Hz}\right)$ of the heterocyclic $\mathrm{H}-2$ and $\mathrm{H}-3$ protons and additional methylene $(\delta 2.53$ and 3.26) and methine ( $\delta 4.16$ and 4.92) proton resonances, respectively. The HMBC spectrum of $\mathbf{8 a}$ and $\mathbf{9 a}$ strongly favored the $4 \rightarrow 8$ interflavonoid bond and the existence of a phenylpropanoid substituent linked to the C-8(A) of the "upper" flavan units in both compounds. Furthermore, 2D correlations between H-6(A), H-7", and H-8" and the carbon C-8(A) at $\delta 110.2$ for $\mathbf{8 a}$ and 111.6 for 9a strongly favored the existence of a phenylpropanoid substituent linked to the C-8 (A) of the "upper" flavan units in 8a and 9a.

The relative configuration of $\mathbf{8} \mathbf{a}$ was determined based on anisotropic effects by comparison of ${ }^{1} \mathrm{H}$ NMR data with those of the peracetate of procyanidin B2. The downfield shift of the $\mathrm{H}-2(\mathrm{C})$ resonance at $\delta 5.86$ and the upfield shift of the B-ring proton resonances $\mathrm{H}-2^{\prime}$ and $\mathrm{H}-6^{\prime}$ at $\delta 6.96(\mathrm{~d}, J 2.1 \mathrm{~Hz})$ and $\delta 7.05(\mathrm{dd}, J 2.1$ and $8.4 \mathrm{~Hz})$ for $\mathbf{8 a}$, respectively, in comparison to the equivalent protons in procyanidin B2 supported the $S$-configuration at C-7". In addition, the $4 \beta \rightarrow 8$-linkage and thus the $R$-configuration at C-4(C) was confirmed by the strong positive Cotton effect observed between 220 and $230 \mathrm{~nm}$, and $280 \mathrm{~nm}$ in the CD spectrum. ${ }^{22-27}$ The missing NOE effect between $\mathrm{H}-2(\mathrm{C})$ and $\mathrm{H}-4$ (C) strongly supported the proposed $4 \beta$ orientation of the interflavanoid bond. The high-amplitude positive Cotton effect was caused by the phenylpropanoid substituent with an S-configuration at C-7". No NOE effect between H-7" and $\mathrm{H}-2$ (C) was observed, confirming the information from the CD data. Thus, it was concluded that the structure of compound $\mathbf{8}$ corresponds to cinchonain IIb.

The absolute configuration of the $\beta$-methine carbon in 9a was determined based on CD data and NOESY NMR experiments. In general, the $4 S$-linkage between two flavan units produces negative Cotton effects at 220-240 and $275 \mathrm{~nm}$ in the CD spectra. ${ }^{22-27}$ Such negative Cotton effects can be observed in the spectrum of compound 9a, in addition to a positive Cotton effect at $255 \mathrm{~nm}$. The latter effect is (probably) due to the $S$-configuration of the phenylpropanoid substituent. The $4 \beta \rightarrow 8$ interflavanoidlinkage was determined by the NOESY NMR experiment, where no effect between $\mathrm{H}-2(\mathrm{C})$ and $\mathrm{H}-4(\mathrm{C})$ was observed. Therefore it was concluded that the structure of compound $\mathbf{9}$ is cinchonain IIa.

Physical data from the well documented $\mathbf{8}$ and $\mathbf{9}$ are in good agreement with the literature values. ${ }^{14}$

\section{Antioxidative activity of Trichilia catigua polyphenols}

The antioxidant effects of the polyphenols are mainly due to their redox properties, which allow them to act as reducing agents or hydrogen-atom donors. Thus, natural antioxidants function as free-radical scavengers and chain-breakers, complexers of pro-oxidant metal ions and quenchers of singlet-oxygen formation. ${ }^{28}$ The radical-scavenging properties of polyphenols can be shown by the effects on DPPH radical as a model compound for lipid radicals or lipid peroxide radicals..$^{29,30}$ The effects of the polyphenols isolated from T. catigua bark on the DPPH radical scavenging and their reducing power were therefore examined.

The DPPH radical scavenging activities of all the tested polyphenols were stronger than the effect of ascorbic acid and Trolox (a water-soluble analogue of $\alpha$-tocopherol), as shown in Table 2. The differences between the monomers cinchonain $\mathrm{Ia}$ and $\mathrm{Ib}$ and also between the dimers cinchonain IIb and IIa were not statistically significant. This implies that the stereochemistry does not influence the DPPH radical scavenging activity. According to the literature, the radical scavenging activity of polyphenols is mainly due to the number of hydroxyl groups in the molecule. ${ }^{18,31}$ This could be confirmed, in this study, for compounds

Table 2. Radical scavenging activity of compounds isolated from T. catigua on the DPPH radical

\begin{tabular}{lcc}
\hline Sample & Mean $\mathrm{EC}_{50} /\left(\mu \mathrm{mol} \mathrm{L}^{-1}\right)$ & $\mathrm{RSD} / \%$ \\
\hline Epicatechin & $10.12 \pm 0.24^{\mathrm{a}}$ & 2.43 \\
Procyanidin B2 & $7.95 \pm 0.04^{\mathrm{b}}$ & 0.51 \\
Cinchonain Ia & $7.87 \pm 0.05^{\mathrm{b}}$ & 0.63 \\
Cinchonain Ib & $7.67 \pm 0.23^{\mathrm{b}}$ & 2.98 \\
Cinchonain IIb & $5.05 \pm 0.05^{\mathrm{c}}$ & 0.98 \\
Cinchonain IIa & $5.15 \pm 0.08^{\mathrm{c}}$ & 1.61 \\
Procyanidin C1 & $4.08 \pm 0.01^{\mathrm{c}}$ & 0.28 \\
Ascorbic acid & $30.11 \pm 1.31$ & 4.36 \\
Trolox & $30.10 \pm 0.48$ & 1.59 \\
\hline
\end{tabular}

Equal letters indicate absence of significant difference $(P<0.05)$; different letters indicate significant difference $(P<0.05) ; \mathrm{RSD}=$ relative standard deviation. 
containing only flavan-3-ol units in their structures. However, for the phenylpropanoid substituted flavan-3-ols, the capacity of scavenging DPPH radicals of cinchonain monomers does not differ from procyanidin B2 and the activity of the cinchonain dimers does not differ significantly from procyanidin $\mathrm{C} 1$. Obviously the number of catechol type B-rings to form quinone intermediates is more responsible for the radical scavenging activity than the number of hydroxyl groups, especially A-Ring hydroxyl groups.

The reducing power of a compound may serve as a significant indicator of its potential antioxidative activity, and therefore can reduce the oxidized intermediates of lipid peroxidation processes, so that they can act as primary and secondary antioxidants. ${ }^{32,33}$ The presence of reducing substances causes the reduction of the $\mathrm{Fe}^{3+} /$ ferricyanide complex to the ferrous form. Therefore, $\mathrm{Fe}^{2+}$ can be monitored by measuring the formation of Perl's Prussian blue at $700 \mathrm{~nm} .{ }^{34}$ Figure 2 shows the reducing power of the compounds isolated from T. catigua compared to Trolox and ascorbic acid. Like the radical scavenging activity, the reducing capacity of these compounds depended on the concentration.

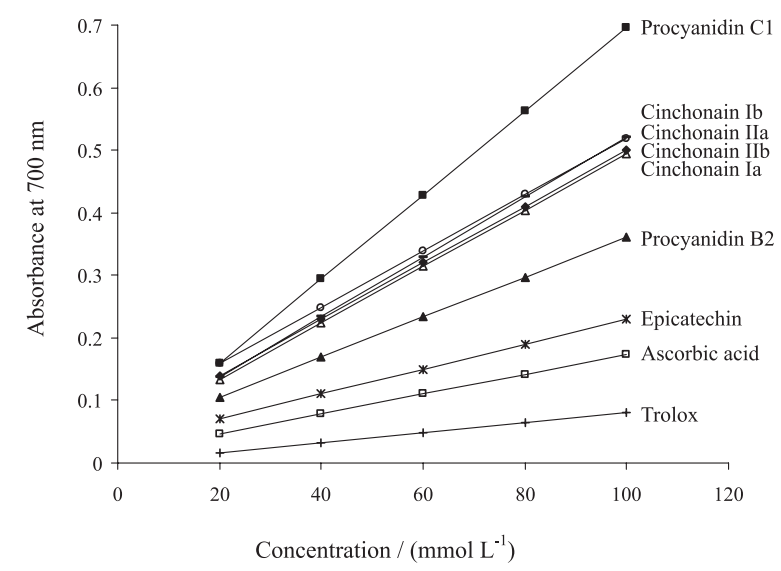

Figure 2. Reducing power of compounds isolated from T. catigua.

The absence of a significant difference $(P<0.05)$ between the reducing capacity of the cinchonain monomers and the cinchonain dimers, in contrast to the series of flavan-3-ol analogues, suggests that the reducing ability of substituted phenylpropanoids is largely unaffected by the number of hydroxyl groups or catechol-type B-rings.

\section{Experimental}

\section{General experimental procedures}

NMR spcetra of the peracetates (Varian Mercury $300 \mathrm{BB})$ were recorded in acetone- $d_{6}$ or $\mathrm{CDCl}_{3}$ at ambient temperature with TMS as internal standard. Some compounds were recorded in $\mathrm{CDCl}_{3}$ to confirm the positions of some protons, or to better define them. ESI-MS was carried out on a Quattro LCZ (Waters-Micromass, Manchester, UK) and HR-ESI-TOF-MS (high resolutionelectrospray ionization-time-of-flight-mass spectroscopy) on a microTof (Bruker-Daltonics, Bremen, Germany). Optical rotations were measured in acetone and CD data were obtained in $\mathrm{MeOH}$ (Jasco 815 spectrometer). Compounds were revealed by spraying with $1 \%$ ethanolic $\mathrm{FeCl}_{3}$ solution. Analytical TLC (thin-layer chromatography) was carried out on precoated aluminum sheets (Kieselgel $60 \mathrm{~F}_{254}$, Merck) with EtOAc/formic acid/ $\mathrm{H}_{2} \mathrm{O}$ (18:1:1; system $\mathrm{Sl}$ ). Preparative TLC was performed on silica gel plates (Kieselgel $60 \mathrm{~F}_{254}, 1.0 \mathrm{~mm}$ ) using toluene $/ \mathrm{Me}_{2} \mathrm{CO}(7: 3$; system S2). Acetylations were performed in pyridine $/ \mathrm{Ac}_{2} \mathrm{O}$ (1:1) at ambient temperature.

\section{Plant material}

Stem bark of T. catigua A. Juss. was collected in January 1997 in Caitité City (Bahia State, Brazil) and identified as described elsewhere. ${ }^{35}$ A voucher specimen is deposited in the Herbarium of the Municipal Botanical Museum of Curitiba City, Paraná State, Brazil (65 901).

\section{Extraction, isolation and identification of compounds}

The data of extraction, isolation and identification of all compounds are presented as supplementary information.

\section{Radical scavenging effects of Trichilia catigua polyphenols on the DPPH radical}

To a DPPH radical solution in $\mathrm{MeOH}\left(1 \mathrm{mmol} \mathrm{L}^{-1}\right.$, $0.3 \mathrm{~mL}$ ), a solution of the test polyphenol in $\mathrm{MeOH}$ $(3.0 \mathrm{~mL})$ was added, and the reaction mixture was left to stand for $30 \mathrm{~min}$ at room temperature. The scavenging activity of each polyphenol at 1, 2, 4, 6, 8 and $10 \mu \mathrm{mol} \mathrm{L}^{-1}$ was estimated by measuring the absorption of the mixture at $517 \mathrm{~nm}$, which reflects the amount of DPPH radical remaining in the solution. The scavenging activity was expressed as the $\mathrm{EC}_{50}(\mu \mathrm{mol} \mathrm{L}-1)$, the concentration of polyphenol required for scavenging $50 \%$ of DPPH radical in the solution. ${ }^{28}$

\section{Reducing power of the polyphenols by $\mathrm{Fe}^{3+}-\mathrm{Fe}^{2+}$} transformation

Different concentrations of the polyphenols (20, 40, 60,80 and $\left.100 \mu \mathrm{mol} \mathrm{L}^{-1}\right)$ in $1 \mathrm{~mL}$ of distilled water were 
mixed with phosphate buffer $\left(2.5 \mathrm{~mL}, 0.2 \mathrm{~mol} \mathrm{~L}^{-1}, \mathrm{pH} 6.6\right)$ and potassium ferricyanide $\left[\mathrm{K}_{3} \mathrm{Fe}(\mathrm{CN})_{6}\right](2.5 \mathrm{~mL}, 1 \%)$. The mixture was incubated at $50{ }^{\circ} \mathrm{C}$ for $20 \mathrm{~min}$. Trichloroacetic acid $(2.5 \mathrm{~mL}, 10 \%)$ was added to the mixture, which was then centrifuged for $10 \mathrm{~min}$ at $1000 \times \mathrm{g}$. The upper layer of solution $(2.5 \mathrm{~mL})$ was mixed with distilled water $(2.5 \mathrm{~mL})$ and $\mathrm{FeCl}_{3}(0.5 \mathrm{~mL}, 0.1 \%)$, and the absorbance was measured at $700 \mathrm{~nm}$. Higher absorbance of the reaction mixture indicated greater reducing power. ${ }^{36}$

\section{Statistical analysis}

Results were assessed by one-way analysis of variance (ANOVA) and represent the mean \pm standard deviation of three different measurements. The significant differences were determined by the Tukey test with $P<0.05$.

\section{Supplementary Information}

The data of extraction, isolation and identification of all compounds are presented as Supplementary Information together with 29 spectra referring to the isolated compounds. Supplementary data are available free of charge at http://jbcs.sbq.org.br as pdf file.

\section{Acknowledgments}

We thank Conselho Nacional de Desenvolvimento Científico e Tecnológico (CNPq), Fundação Araucária, Instituto Nacional de Ciência e Tecnologia para Inovação Farmacêutica (INCT_if), Financiadora de Estudos e Projetos (FINEP) for financial support and Coordenação de Aperfeiçoamento de Pessoal de Nível Superior (CAPES) for a fellowship. Our gratitude to Prof. Dr. W. Villegas (Instituto de Química, Universidade Estadual Paulista, Brazil) for technical support on MLCCC. The technical assistance provided by A. Arantes and C. R. Novello is gratefully acknowledged. Our gratitude is to Dr. J. W. Reid for the English text revising and to Dr. I. T. A. Schuquel for NMR spectra. The valuable observations of anonymous reviewers and Prof. Dr. Daneel Ferreira contributed significantly to the improvements in the manuscript.

\section{References}

1. Klein, R. M.; Flora Ilustrada Catarinense - Meliáceas; Herbário Barbosa Rodrigues: Itajaí, SC, Brasil, 1984, p. 55-60.

2. Marques, L. C.; Racine 1998, 8, 8.

3. Kletter, C.; Glasl, S.; Presser, A.; Werner, I.; Reznicek, G.; Narantuya, S.; Cellek, S.; Haslinger, E.; Jurenitsch, J.; Planta Med. 2004, 70, 993.
4. Daolio, C.; Beltrame, F. L.; Ferreira, A. G.; Cass, Q. B.; Cortez, D. A. G.; Ferreira, M. M. C.; Phytochem. Anal. 2008, 19, 218.

5. Pizzolatti, M. G.; Venson, A. F.; Smânia Júnior, A.; Smânia, E. F. A.; Braz-Filho, R.; Z. Naturforsch. C 2002, 57, 483.

6. Pizzolatti, M. G.; Koga, A. H.; Grisard, E. C.; Steindel, M.; Phytomedicine 2002, 9, 422.

7. Calixto, J. B.; Cabrini, D. A.; Phytother. Res. 1997, 11, 32.

8. Vaz, Z. R.; Mata, L. V.; Calixto, J. B.; Phytother. Res. 1997, 11, 101.

9. Antunes, E.; Gordo, W. M.; De Oliveira, J. F.; Teixeira, C. E.; Hyslop, S.; De Nucci, G.; Phytother. Res. 2001, 15, 416.

10. Campos, M. M.; Fernandes, E. S.; Ferreira, J.; Santos, A. R. S.; Calixto, J. B.; Psychopharmacology 2005, 182, 45.

11. Beltrame, F. L.; Rodrigues Filho, E.; Barros, F. A. P.; Cortez, D. A. G.; Cass, Q. B.; J. Chromatogr., A 2006, 1119, 257.

12. Pupo, M. T.; Adorno, M. A. T.; Vieira, P. C.; Fernandes, J. B.; Silva, M. F. G. F.; Pirani, J. R.; J. Braz. Chem. Soc. 2002, 13, 382.

13. Nonaka, G.-I.; Nishioka, I.; Chem. Pharm. Bull. 1982, 30, 4268.

14. Nonaka, G.-I.; Kawahara, O.; Nishioka, I.; Chem. Pharm. Bull. 1982, 30, 4277.

15. Chen, H.-F.; Tanaka, T.; Nonaka, G.-I.; Fujioka, T.; Mihashi, K.; Phytochemistry 1993, 33, 183.

16. Tabanca, N.; Pawar, R. S.; Ferreira, D.; Marais, J. P. J.; Khan, S. I.; Joshi, V.; Wedge, D. E.; Khan, I. A.; Planta Med. 2007, 73, 1107.

17. Yamaguti-Sasaki, E.; Ito, L. A.; Canteli, V. C. D.; Ushirobira, T. M. A.; Ueda-Nakamura, T.; Dias Filho, B. P.; Nakamura, C. V.; Mello, J. C. P.; Molecules 2007, 12, 1950.

18. Takara, K.; Kuniyoshi, A.; Wada, K.; Kinjyo, K.; Iwasaki, H.; Biosci., Biotechnol., Biochem. 2008, 72, 2191.

19. Foo, L. Y.; Phytochemistry 1987, 26, 2825.

20. Ming, D. S.; López, A.; Hillhouse, B. J.; French, C. J.; Hudson, J. B.; Towers, G. H. N.; J. Nat. Prod. 2002, 65, 1412.

21. Tang, W.; Hioki, H.; Harada, K.; Kubo, M.; Fukuyama, Y.; J. Nat. Prod. 2007, 70, 2010.

22. Korver, O.; Wilkins, C. K.; Tetrahedron 1971, 27, 5459.

23. Thompson, R. S.; Jacques, D.; Haslam, E.; Tanner, R. J. N.; J. Chem. Soc., Perkin Trans. 1 1972, 1387.

24. Botha, J. J.; Ferreira, D.; Roux, D. G.; J. Chem. Soc., Chem. Commun. 1978, 698.

25. Botha, J. J.; Young, D. A.; Ferreira, D.; Roux, D. G.; J. Chem. Soc., Perkin Trans. 1 1981, 1213.

26. Barrett, M. W.; Klyne, W.; Scopes, P. M.; Fletcher, A. C.; Porter, L. J.; Haslam, E.; J. Chem. Soc., Perkin Trans. 1 1979, 2375.

27. Palazzo de Mello, J.; Petereit, F.; Nahrstedt, A.; Phytochemistry 1996, 41, 807.

28. Amarowicz, R.; Pegg, R. B.; Rahimi-Moghaddam, P.; Barl, B.; Weil, J. A.; Food Chem. 2004, 84, 551. 
29. Hatano, T.; Edamatsu, R.; Hiramatsu, M.; Mori, A.; Fujita, Y.; Yasuhara, T.; Yoshida, T.; Okuda, T.; Chem. Pharm. Bull. 1989, 37, 2016

30. Yoshida, T.; Mori, K.; Hatano, T.; Okumura, T.; Uehara, I.; Komagoe, K.; Fujita, Y.; Okuda, T.; Chem. Pharm. Bull. 1989, 37, 1919.

31. Pellati, F.; Benvenuti, S.; Magro, L.; Melegari, M.; Soragni, F.; J. Pharm. Biomed. Anal. 2004, 35, 289.

32. Chung, Y. C.; Chang, C. T.; Chao, W. W.; Lin, C. F.; Chou, S. T.; J. Agric. Food Chem. 2002, 50, 2454.
33. Hong, Y.; Qiao, Y.; Lin, S.; Jiang, Y.; Chen, F.; Sci. Hortic. 2008, $118,288$.

34. Yen, G.-C.; Chen, H.-Y.; J. Agric. Food Chem. 1995, 43, 27.

35. Souza, L. A.; Moscheta, I. S.; Mourão, K. S. M.; Silvério, A.; Braz. Arch. Biol. Technol. 2001, 44, 383.

36. Gülçin, I.; Life Sci. 2006, 78, 803.

Submitted: July 16, 2010

Published online: September 6, 2011

FAPESP has sponsored the publication of this article. 


\title{
Phenylpropanoid Substituted Flavan-3-ols from Trichilia catigua and their in vitro Antioxidative Activity
}

\author{
Flávia O. Resende, ${ }^{a}$ Edson Rodrigues-Filho, ${ }^{b}$ Heinrich Luftmann, ${ }^{c}$ \\ Frank Petereit ${ }^{d}$ and João C. Palazzo de Mello ${ }^{*, a}$ \\ aPrograma de Pós-Graduação em Ciências Farmacêuticas, Universidade Estadual de Maringá, \\ Av. Colombo No. 5790, 87020-900 Maringá-PR, Brazil \\ ${ }^{b}$ Departamento de Química, Universidade Federal de São Carlos, \\ Rod. Washington Luiz, $\mathrm{km}$ 235, 13905-905 São Carlos-SP, Brazil \\ 'Organisch-Chemisches Institut, Universität Münster, Corrensstrasse 40, \\ D-48149, Münster, Germany \\ ${ }^{d}$ Institut für Pharmazeutische Biologie und Phytochemie, Universität Münster, \\ Hittorfstrasse 56, D-48149, Münster, Germany
}

Extraction, isolation and identification of compounds

Air-dried stem bark (500 g) was extracted with $\mathrm{Me}_{2} \mathrm{CO} / \mathrm{H}_{2} \mathrm{O}(7: 3,5.0 \mathrm{~L})$. The combined extracts were filtered and evaporated under reduced pressure to $0.5 \mathrm{~L}$ and lyophilized $(71 \mathrm{~g})$. This fraction was redissolved in $710 \mathrm{~mL}$ $\mathrm{H}_{2} \mathrm{O}$ and extracted with EtOAc $(8.5 \mathrm{~L})$. After evaporation of solvents, the EtOAc extract and the remaining $\mathrm{H}_{2} \mathrm{O}$ phase gave dark-brown solids of 24 and $47 \mathrm{~g}$, respectively. A portion (13 g) of the EtOAc extract was subjected to column chromatography (CC) on Sigma-Sephadex ${ }^{\circledR}$ LH-20 $(500 \times 60 \mathrm{~mm}$; eluents: $30 \% \mathrm{EtOH}(6.7 \mathrm{~L})$, $40 \% \mathrm{EtOH}(3.2 \mathrm{~L}), 50 \% \mathrm{EtOH}(4 \mathrm{~L}), 70 \% \mathrm{EtOH}(1.3 \mathrm{~L})$, $\mathrm{EtOH}(1.5 \mathrm{~L}), 50 \% \mathrm{MeOH}(1 \mathrm{~L}), \mathrm{MeOH}(1 \mathrm{~L})$ and $70 \%$ $\mathrm{Me}_{2} \mathrm{CO}(3 \mathrm{~L}) ; 10 \mathrm{~mL}$ fractions) to yield 32 main fractions (indicated below with roman numerals). All main fractions were further separated by high-speed countercurrent chromatography (HSCCC), which was carried out with the solvent system EtOAc/n-PrOH/ $\mathrm{H}_{2} \mathrm{O}$ (140:8:80) on a P. C. Inc. high-speed countercurrent separator-extractor,

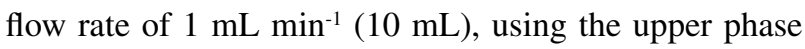
as mobile phase (these fractions are indicated below with asterisks). Unresolved subfractions were subjected to TLC (thin-layer chromatography) preparation using toluene/ $\mathrm{Me}_{2} \mathrm{CO}$ (7:3; system $\left.\mathrm{S} 2\right)$.

*e-mail:mello@uem.br

\section{Epicatechin (1)}

Fraction XII (test tubes 671-765; $265 \mathrm{mg}$ ) was subjected to a new CC on Sephadex ${ }^{\circledR}$ LH $20(25 \times 270 \mathrm{~mm}$; eluents $5 \% \operatorname{EtOH}(1 \mathrm{~L}), 10 \% \operatorname{EtOH}(0.5 \mathrm{~L}), 15 \% \mathrm{EtOH}(0.5 \mathrm{~L})$, and $70 \%$ acetone $(0.5 \mathrm{~L}) ; 3 \mathrm{ml}$ fractions) to yield 4 subfractions. Subfraction 3 (test tubes 320-485; $113 \mathrm{mg}$ ) was identified as epicatechin, a light-yellow amorphous powder; $[\alpha]_{\mathrm{D}}^{20^{\circ}}-8(c 0.1, \mathrm{MeOH})$; ESI-MS at $m / z 313\left([\mathrm{M}+\mathrm{Na}]^{+}\right)$. These data are for the free phenol; the ${ }^{1} \mathrm{H}$ NMR data are identical to those of an authentic sample as peracetate in acetone- $d_{6}(\mathbf{1 a})$, see Table 1 .

Procyanidin B2 (2)

Fraction XVI (test tubes 920-999; $514 \mathrm{mg}$ ) was subjected to HSCCC to yield five subfractions. Subfraction 4 (test tubes 75-108; $256 \mathrm{mg}$ ) was identified as procyanidin B2, a light-brown amorphous powder; $[\alpha]_{\mathrm{D}}^{20^{\circ}}+3(c 0.1, \mathrm{MeOH})$; ESI-MS at $m / z 577.4\left([\mathrm{M}-\mathrm{H}]^{-}\right), 601.5\left([\mathrm{M}+\mathrm{Na}]^{+}\right)$. These data are for the free phenol. $\mathrm{CD}(c 0.02, \mathrm{MeOH}$, peracetate): $[\theta]_{240}+11380,[\theta]_{280}+7910$; the ${ }^{1} \mathrm{H}$ NMR data are identical to those of an authentic sample as peracetate; ${ }^{17,23}{ }^{13} \mathrm{C} \mathrm{NMR}$ $\left(\mathrm{CDCl}_{3}, 75 \mathrm{MHz}\right) \delta 155.3$ (C, C-5(A)), 154.2 (C, C-9(D)), 149.1 (C, C-7(A)), 149.0 (C, C-5(D)), 147.9 (C, C-9(A)), 147.8 (C, C-7(D)), 141.7 and $142.0^{\mathrm{a}}$ (C, C-3' and C, C-4'(E)), 141.6 ${ }^{\mathrm{b}}$ and $141.9^{\mathrm{b}}$ (C, C-3' and C, C-4'(B)), 136.5 (C, C-1'(B)), $134.4\left(\mathrm{C}, \mathrm{C}-1^{\prime}(\mathrm{E})\right), 125.0(\mathrm{CH}, \mathrm{C}-6$ ' $(\mathrm{E}))$, $124.4\left(\mathrm{CH}, \mathrm{C}-6^{\prime}(\mathrm{B})\right), 123.1\left(\mathrm{CH}, \mathrm{C}-5^{\prime}(\mathrm{B})\right), 122.8(\mathrm{CH}$, C-5'(E)), 122.4 (CH, C-2'(E)), 122.2 (CH, C-2'(B)), 116.7 (C, C-8(D)), 111.7 (C, C-10(D)), 111.6 (C, C-10(A)), 110.3 
(CH, C-6(D)), 108.6 (CH, C-8(A)), 107.2 (CH, C-6(A)), $77.1(\mathrm{CH}, \mathrm{C}-2(\mathrm{~F})), 73.6(\mathrm{CH}, \mathrm{C}-2(\mathrm{C})), 71.0(\mathrm{CH}, \mathrm{C}-3(\mathrm{C}))$, 66.8 (CH, H-3(F)), 33.9 (CH, C-4(C)), $26.6\left(\mathrm{CH}_{2}, \mathrm{C}-4(\mathrm{~F})\right)$; $\mathrm{a}$ and $\mathrm{b}=$ interchangeable.

\section{Procyanidin B4 (3)}

Fraction XVII (test tubes 1000-1080; $767 \mathrm{mg}$ ) was subjected to a new CC on Sephadex ${ }^{\circledR}$ LH $20(34 \times 340 \mathrm{~mm}$; eluents $1 \% \mathrm{EtOH}(1.3 \mathrm{~L}), 3 \% \mathrm{EtOH}(0.6 \mathrm{~L}), 5 \% \mathrm{EtOH}$ $(0.2 \mathrm{~L}), 8 \% \mathrm{EtOH}(0.5 \mathrm{~L}), 12 \% \mathrm{EtOH}(1.2 \mathrm{~L}), 14 \%$ EtOH (0.5 L), 16\% EtOH (1.2 L), $18 \%$ EtOH (3.0 L), $20 \% \mathrm{EtOH}(1.0 \mathrm{~L}), 25 \% \mathrm{EtOH}(0.7 \mathrm{~L}), 40 \% \mathrm{EtOH}$ $(1.0 \mathrm{~L})$, and $\mathrm{Me}_{2} \mathrm{CO}(0.7 \mathrm{~L} ; 4 \mathrm{~mL}$ fractions $)$ to yield 15 subfractions. Subfraction 11 was peracetylated and purified by preparative TLC (system $\mathrm{S} 2, \mathrm{R}_{f} 0.33$ ) to give $16 \mathrm{mg}$ of compound 3a, a light-brown amorphous powder. 3a: $[\alpha]_{\mathrm{D}}^{20^{\circ}}-14.6$ ( $c$ 0.13, $\left.\mathrm{Me}_{2} \mathrm{CO}\right)$. ESI-MS at $m / z 997.5$ $\left([\mathrm{M}-\mathrm{H}]^{-}\right), 1021.5\left([\mathrm{M}+\mathrm{Na}]^{+}\right) ; \mathrm{CD}(c 0.1 ; \mathrm{MeOH})$ : $[\theta]_{240}-4280,[\theta]_{280}-7140$; the ${ }^{1} \mathrm{H}$ NMR data are identical to those published by Thompson et $a .^{23}$ and Yamaguti-Sasaki et $a l ;{ }^{17}{ }^{13} \mathrm{C}$ NMR (acetone- $d_{6}, 75 \mathrm{MHz}$ ) $\delta 156.7$ (C, C-9(C)), 154.6 (C, C-9(D)), 150.7 (C, C-5(A)), 150.5 (C, C-7(A)), 149.5 (C, C-5(D)), 148.9 (C, C-7(D)), $143.4^{\mathrm{a}}, 143.2^{\mathrm{a}}, 143.0^{\mathrm{a}}$ and $142.8^{\mathrm{a}}\left(2 \times \mathrm{C}, \mathrm{C}-3^{\prime}(\mathrm{B} / \mathrm{E})\right.$ and $\left.2 \times \mathrm{C}, \mathrm{C}-4^{\prime}(\mathrm{B} / \mathrm{E})\right), 136.9\left(\mathrm{C}, \mathrm{C}-1^{\prime}(\mathrm{E})\right), 136.8\left(\mathrm{C}, \mathrm{C}-1^{\prime}(\mathrm{B})\right)$, $126.0\left(\mathrm{CH}, \mathrm{C}-6^{\prime}(\mathrm{E})\right), 125.7\left(\mathrm{CH}, \mathrm{C}-6{ }^{\prime}(\mathrm{B})\right), 124.4(\mathrm{CH}$, C-5'(B)), $123.9\left(\mathrm{CH}, \mathrm{C}^{\prime} 5^{\prime}(\mathrm{E})\right), 123.7$ (CH, C-2'(B)), 123.1 (CH, C-2'(E)), 118.4 (C, C-8(D)), 116.6 (C, C-10(A)), 111.9 (C, C-10(D)), 111.3 (CH, C-6(A)), 110.7 (CH, C-6(D)), 109.0 (CH, C-8(A)), $79.5(\mathrm{CH}, \mathrm{C}-4(\mathrm{C})), 78.2(\mathrm{CH}$, C-2(F)), $70.9(\mathrm{CH}, \mathrm{C}-3(\mathrm{C})), 67.6(\mathrm{CH}, \mathrm{C}-3(\mathrm{~F})), 37.4(\mathrm{CH}$, $\mathrm{C}-2(\mathrm{C})), 27.3\left(\mathrm{CH}_{2}, \mathrm{C}-4(\mathrm{~F})\right)$; a and $\mathrm{b}=$ interchangeable.

\section{Procyanidin C1 (4)}

Fraction XXI (test tubes 1371-1440; $347 \mathrm{mg}$ ) was subjected to HSCCC to yield six subfractions. Subfraction 5 (test tubes 96-102; $19 \mathrm{mg}$ ) was identified as procyanidin C1 by comparison of physical data of its peracetate. Compound $\mathbf{4}$ is a light-brown amorphous powder; $[\alpha]_{\mathrm{D}}^{20^{\circ}}+7(c 0.1, \mathrm{MeOH}) ; \mathrm{ESI}-\mathrm{MS}$ at $m / z 865.5\left([\mathrm{M}-\mathrm{H}]^{-}\right)$, $889.4\left([\mathrm{M}+\mathrm{Na}]^{+}\right) ; \mathrm{CD}(c 0.02, \mathrm{MeOH}):[\theta]_{240}+2527$, $[\theta]_{280}+1863$. 4a: ${ }^{1} \mathrm{H}$ NMR data are identical to those published by Yamaguti-Sasaki et al: $;{ }^{13} \mathrm{C} \mathrm{NMR}\left(\mathrm{CDCl}_{3}\right.$, $75 \mathrm{MHz}) \delta 111.2(\mathrm{CH}, \mathrm{C}-6(\mathrm{G})), 110.9(\mathrm{CH}, \mathrm{C}-6(\mathrm{D})), 107.7$ (CH, C-8(A)), $107.6(\mathrm{CH}, \mathrm{C}-6(\mathrm{~A})), 77.2^{\#}(\mathrm{CH}, \mathrm{C}-2(\mathrm{I}))$, 77.2\# (CH, C-3(C)), $75.2(\mathrm{CH}, \mathrm{C}-3(\mathrm{~F})), 70.7(\mathrm{CH}, \mathrm{C}-2(\mathrm{C}))$, 66.8 (CH, C-3(I)), 35.8 (CH, C-4(C)), 35.3 (CH, C-4(F)), $34.6(\mathrm{CH}, \mathrm{C}-2(\mathrm{~F})), 26.6\left(\mathrm{CH}_{2}, \mathrm{C}-4(\mathrm{I})\right)$; \# = overlapping.

\section{Cinchonain Ia (5)}

Fraction XVIII (test tubes 1081-1112; $353 \mathrm{mg}$ ) was subjected to HSCCC to yield eight subfractions. Subfraction 2 (test tubes 19-22; $136 \mathrm{mg}$ ) was identified as cinchonain Ia, a white amorphous powder; $[\alpha]_{\mathrm{D}}^{20^{\circ}}-35(c 0.1, \mathrm{MeOH})$; ESI-MS at $m / z 451.4\left([\mathrm{M}-\mathrm{H}]^{-}\right), 475.3\left([\mathrm{M}+\mathrm{Na}]^{+}\right)$; CD (c 0.002, MeOH): $[\theta]_{234}-22741,[\theta]_{255}+5053,[\theta]_{280}-20214$. 5a: ${ }^{1} \mathrm{H}$ NMR (acetone- $d_{6}, 300 \mathrm{MHz}$ ): see Table $1 ;{ }^{13} \mathrm{C}$ NMR (acetone- $\left.d_{6}, 75 \mathrm{MHz}\right) \delta 167.3$ (CO, C-9"), 152.6 (C, C-9), 151.7 (COC, C-7), 150.7 (C, C-5), 143.5 (C, C-3”), 143.4 (C, C-3'), 143.1 (C, C-4'), 142.5 (C, C-4”), 141.3 (C, C-1"), 137.1 (C, C-1'), 125.4 (CH, C-6'), 125.3 (CH, C-2'), 124.2 (CH, C-5'), 124.9 (CH, C-6"), 123.1 (CH, C-5"), 122.8 (CH, C-2'), 111.5 (C, C-8), 109.9 (C, C-10), 104.8 (CH, C-6), 77.6 (CH, C-2), 67.1 (CH, C-3), 36.7 ( $\mathrm{CH}_{2}, \mathrm{C}-8$ "), 35.1 (CH, C-7’), $26.6\left(\mathrm{CH}_{2}, \mathrm{C}-4\right)$.

\section{Cinchonain Ib (6)}

Fraction XIX (test tubes 1113-1295; $707 \mathrm{mg}$ ) was subjected to HSCCC to yield six subfractions. Subfraction 2 (test tubes 23-25; $292 \mathrm{mg}$ ) was identified as cinchonain Ib, a light-brown amorphous powder; $[\alpha]_{\mathrm{D}}^{20^{\circ}}+3(c 0.1, \mathrm{MeOH})$; ESI-MSat $m / z 451.4\left([\mathrm{M}-\mathrm{H}]^{-}\right), 475.4\left([\mathrm{M}+\mathrm{Na}]^{+}\right)$; CD (c 0.002, MeOH): $[\theta]_{234}+3369,[\theta]_{255}-1212,[\theta]_{280}+1347$. 6a: ${ }^{1} \mathrm{H}$ NMR (acetone- $d_{6}, 300 \mathrm{MHz}$ ): see Table $1 ;{ }^{13} \mathrm{C}$ NMR (acetone- $\left.d_{6}, 75 \mathrm{MHz}\right): \delta 167.1$ (CO, C-9"), 152.6 (C, C-9), 152.0 (COC, C-7), 150.8 (C, C-5), 143.7 (C, C-3”), 143.2 (C, C-3'), 143.1 (C, C-4'), 142.6 (C, C-4”), 141.2 (C, C-1”), 137.2 (C, C-1'), 125.8 (CH, C-6'), 125.4 (CH, C-2”), 124.8 (CH, C-6”), 124.2 (CH, C-5'), 122.9 (CH, C-2'), 123.2 (CH, C-5”), 111.1 (C, C-8), 109.7 (C, C-10), 104.5 (CH, C-6), 78.1 (CH, C-2), 67.3 (CH, C-3), 36.5 ( $\mathrm{CH}_{2}, \mathrm{C}-8$ ”), 34.9 (CH, C-7”), $26.5\left(\mathrm{CH}_{2}, \mathrm{C}-4\right)$.

\section{Cinchonain IIb (8)}

Fraction XIX (test tubes 1113-1295; $707 \mathrm{mg}$ ) was subjected to HSCCC to yield six subfractions. Subfraction 4 (test tubes 42-58; $60.4 \mathrm{mg}$ ) was identified as cinchonain IIb, a light-brown amorphous powder; $[\alpha]_{\mathrm{D}}^{20^{\circ}}+22(c 0.1, \mathrm{MeOH})$; ESI-MS at $m / z 739.4\left([\mathrm{M}-\mathrm{H}]^{-}\right)$, $763.4\left([\mathrm{M}+\mathrm{Na}]^{+}\right) ; \mathrm{CD}(c 0.002, \mathrm{MeOH}):[\theta]_{234}-49617$, $[\theta]_{255}+2756,[\theta]_{280}+11026$. 8a: ${ }^{1} \mathrm{H}$ NMR (acetone- $d_{6}$, $300 \mathrm{MHz}) \delta 7.28(\mathrm{~d}, 1 \mathrm{H}, J 8.7 \mathrm{~Hz}, \mathrm{H}-5$ ”), 7.28 (dd, 1H, J 2.7, 6.3 Hz, H-6'(E)), 7.23 (d, 1H, J 1.8 Hz, H-2'(E)), $7.22\left(\mathrm{~d}, 1 \mathrm{H}, J 8.4 \mathrm{~Hz}, \mathrm{H}-5^{\prime}(\mathrm{E})\right), 7.17$ (d, 1H, J $8.4 \mathrm{~Hz}$, H-5'(B)), 7.10 (dd, 1H, J 2.4, 8.7 Hz, H-6”), 7.05 (dd, 1H, J 2.1, 8.4 Hz, H-6'(B)), 6.96 (d, 1H, J 2.1 Hz, H-2'(B)), 6.88 (d, 1H, J 2.4 Hz, H-2”), 6.76 (s, 1H, H-6(D)), 6.40 (s, 
1H, H-6(A)), 5.86 (brs, 1H, H-2(C)), 5.24 (m, 1H, H-3(F)), 5.17 (m, 1H, H-3(C)), 4.89 (brs, 1H, H-2(F)), 4.54 (d, 1H, $J 1.8 \mathrm{~Hz}, \mathrm{H}-4(\mathrm{C})), 4.16$ (1H, brd, $\Sigma J 6.6 \mathrm{~Hz}, \mathrm{H}-7$ '), 2.98 $\left(1 \mathrm{H}, \mathrm{dd}, J 4.5,17.7 \mathrm{~Hz}, \mathrm{H}-4_{\mathrm{eq}}(\mathrm{F})\right), 2.85\left(1 \mathrm{H}, \mathrm{m}, \mathrm{H}-4_{\mathrm{ax}}(\mathrm{F})\right)$, $2.78\left(\mathrm{dd}, 1 \mathrm{H}, J 1.5,16.5 \mathrm{~Hz}, \mathrm{H}-8{ }^{\prime}{ }_{\text {eq }}\right.$ ), 2.28 (dd, $1 \mathrm{H}, J 0.9$, $16.5 \mathrm{~Hz}, \mathrm{H}-8{ }_{\mathrm{ax}}$ ); ${ }^{13} \mathrm{C}$ NMR (acetone- $\left.d_{6}, 75 \mathrm{MHz}\right) \delta 167.1$ (CO, C-9"), 154.7 (C, C-9(D)), 152.8 (C, C-9(A)), 150.6 (C, C-7(D)), 150.4 (COC, C-7(A)), 149.6 (C, C-5(A)), $149.2^{\mathrm{b}}(\mathrm{C}, \mathrm{C}-5(\mathrm{D})), 143.6^{\mathrm{d}}\left(\mathrm{C}, \mathrm{C}-3^{\prime}\right), 143.4^{\mathrm{c}}\left(\mathrm{C}, \mathrm{C}-4^{\prime}(\mathrm{B})\right)$, $143.3^{\mathrm{c}}\left(\mathrm{C}, \mathrm{C}-3^{\prime}(\mathrm{B})\right), 143.2^{\mathrm{e}}$ (C, C-3'(E)), 142.9 (C, C-4"), $142.4^{\mathrm{e}}$ (C, C-4'(E)), 141.6 (C, C-1"), 136.9 (C, C-1'(E)), 136.8 (C, C-1'(B)), 126.1 (CH, C-6”), 125.6 (CH, C-6'(B)), $125.3\left(\mathrm{CH}, \mathrm{C}^{\prime}{ }^{\prime}(\mathrm{E})\right), 124.6\left(\mathrm{CH}, \mathrm{C}-2^{\prime}(\mathrm{E})\right), 124.4(\mathrm{CH}$, C-5'(B)), 124.2 (CH, C-5"), 123.3 (CH, C-5'(E)), 123.2 (CH, C-2'(B)), 122.6 (CH, C-2"), 117.2 (C, C-8(D)), 112.5 (C, C-10(D)), 111.7 (C, C-10(A)), 111.5 (CH, C-6(D)), 110.2 (C, C-8(A)), $104.8(\mathrm{CH}, \mathrm{C}-6(\mathrm{~A})), 77.9(\mathrm{CH}, \mathrm{C}-2(\mathrm{~F}))$, $75.8(\mathrm{CH}, \mathrm{C}-2(\mathrm{C})), 71.3(\mathrm{CH}, \mathrm{C}-3(\mathrm{C})), 67.3(\mathrm{CH}, \mathrm{C}-3(\mathrm{~F}))$, $36.9\left(\mathrm{CH}_{2}, \mathrm{C}-8\right.$ "), $35.0(\mathrm{CH}, \mathrm{C}-4(\mathrm{C})), 34.6$ (CH, C-7”), 26.9 $\left(\mathrm{CH}_{2}, \mathrm{C}-4(\mathrm{~F})\right) ; \mathrm{a}, \mathrm{b}, \mathrm{c}, \mathrm{d}, \mathrm{e}=$ interchangeable.

\section{Cinchonain IIa (9)}

Fraction XXI (test tubes 1371-1440; $347 \mathrm{mg}$ ) was subjected to HSCCC to yield six subfractions. Subfraction 3 (test tubes $51-55 ; 31 \mathrm{mg}$ ) was identified as compound 9. A light-brown amorphous powder; $[\alpha]_{\mathrm{D}}^{20^{\circ}}-5(\mathrm{c} 0.1$, acetone); ESI-MS at $m / z 739.4\left([\mathrm{M}-\mathrm{H}]^{-}\right), 763.4\left([\mathrm{M}+\mathrm{Na}]^{+}\right)$ and at $\mathrm{m} / z 1220.4\left[\mathrm{M}+\mathrm{NH}_{4}\right]^{+}$; HR-ESI-MS positive-ion mode at $m / z 619.1785\left[\left(\text { calcd for } \mathrm{C}_{61} \mathrm{H}_{54} \mathrm{O}_{26}+2 \mathrm{NH}_{4}\right)^{2+}\right.$ 619.1789]; $\mathrm{CD}(c 0.002, \mathrm{MeOH}):[\theta]_{234}-15160,[\theta]_{255}+9096$, $[\theta]_{280}-13645.9 \mathrm{a}:{ }^{1} \mathrm{H}$ NMR (acetone- $\left.d_{6}, 300 \mathrm{MHz}\right) \delta 7.45$ (d, 1H, J $1.8 \mathrm{~Hz}, \mathrm{H}-2$ '(E)), 7.36 (m, 3H, H-5'(B,E), H-2'(B)), 7.30 (dd, 1H, J 1.8, 8.7 Hz, H-6'(B)), 7.22 (dd, $1 \mathrm{H}, J 1.8,8.4 \mathrm{~Hz}, \mathrm{H}-6$ '(E)), 7.22 (dd, $1 \mathrm{H}, J 1.8,8.4 \mathrm{~Hz}$, H-6'(E)), 7.12 (m, 3H, H-2", H-5", H-6"), 6.64 (s, 1H, H-6(A)), 6.61 (s, 1H, H-6(D)), 5.67 (m, 1H, H-3(F)), 5.41 (brs, 1H, H-2(C)), 5.40 (brs, 1H, H-2(F)), 5.34 (m, 1H,

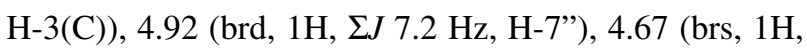

$\mathrm{H}-4(\mathrm{C})), 3.52$ (dd, $1 \mathrm{H}, J 7.8$ and $\left.16.5 \mathrm{~Hz}, \mathrm{H}-8{ }^{\prime}{ }_{\mathrm{ax}}(\mathrm{F})\right), 3.20$ (dd, $\left.1 \mathrm{H}, J 1.8,4.5 \mathrm{~Hz}, \mathrm{H}-4_{\mathrm{eq}}(\mathrm{F})\right), 3.01\left(\mathrm{~m}, 1 \mathrm{H}, \mathrm{H}-8{ }{ }_{\mathrm{eq}}\right.$ ), $2.88\left(\mathrm{~m}, 1 \mathrm{H}, \mathrm{H}-4_{\mathrm{ax}}(\mathrm{F})\right) ;{ }^{13} \mathrm{C}$ NMR (acetone- $d_{6}, 75 \mathrm{MHz}$ ) $\delta 167.8$ (CO, C-9"), 152.7 (C, C-9(D)), 152.4 (COC, C-7(A)), 151.1 (C, C-9(A)), 150.7 (C, C-5(A)), 149.7ª (C, C-7(D)), 148.4 (C, C-5(D)), 143.5 ${ }^{\mathrm{b}}, 143.3^{\mathrm{b}}, 143.3^{\mathrm{b}}, 143.1^{\mathrm{b}}$, $142.8^{\mathrm{b}}$ and $142.7^{\mathrm{b}}\left(4 \times \mathrm{C}, \mathrm{C}-3^{\prime}, 4^{\prime}\right.$ (B/E) and $\left.2 \times \mathrm{C}, \mathrm{C}-3^{\prime \prime}, 4^{\prime \prime}\right)$, 141.9 (C, C-1"), $137.4^{\mathrm{c}}$ and $136.3^{\mathrm{c}}\left(2 \times \mathrm{C}, \mathrm{C}-1^{\prime} \mathrm{B} / \mathrm{E}\right)$, $125.1\left(\mathrm{CH}, \mathrm{C}-6^{\prime}(\mathrm{B})\right), 125.4^{\mathrm{d}}, 125.1^{\mathrm{d}}$ and $124.1^{\mathrm{d}}(3 \times \mathrm{CH}$, C-2",5",6"), $124.2\left(\mathrm{CH}, \mathrm{C}-6^{\prime}(\mathrm{E})\right), 122.8\left(\mathrm{CH}, \mathrm{C}-2^{\prime}(\mathrm{E})\right)$, $122.5^{\#}\left(\mathrm{CH}, \mathrm{C}-2^{\prime}(\mathrm{B})\right), 122.5^{\#}\left(\mathrm{CH}, \mathrm{C}-5^{\prime}(\mathrm{B})\right), 122.5^{\#}(\mathrm{CH}$, C-5'(E)), 118.4 (C, C-8(A)), 112.1 (C, C-10(A)), 111.9 (C, C-10(D)), 111.6 (CH, C-6(D)), 111.2 (C, C-8(D)), 105.3 (CH, C-6(A)), $77.6(\mathrm{CH}, \mathrm{C}-2(\mathrm{~F})), 75.8(\mathrm{CH}, \mathrm{C}-2(\mathrm{C})), 72.1$ (CH, C-3(C)), $67.3(\mathrm{CH}, \mathrm{C}-3(\mathrm{~F})), 35.6^{*}\left(\mathrm{CH}_{2}, \mathrm{C}-8^{\prime \prime}\right), 35.6^{\#}$ (CH, C-4(C)), 35.5 (CH, C-7"), $26.8\left(\mathrm{CH}_{2}, \mathrm{C}-4(\mathrm{~F})\right)$; a, b, $\mathrm{c}, \mathrm{d}=$ interchangeable and $\#=$ overlapping.

Apocynin E (7)

Fraction XVIII (test tubes 1081-1112; $353 \mathrm{mg}$ ) was subjected to HSCCC to yield eight subfractions. Subfraction 3 (test tubes $23-36 ; 45 \mathrm{mg}$ ) was peracetylated and purified by preparative TLC (system S2, $R_{\mathrm{f}} 0.31$ ) to give $15 \mathrm{mg}$ of compound 7a. 7a: A light-brown amorphous powder; $[\alpha]_{\mathrm{D}}^{20^{\circ}}+6.2(c 0.08$, acetone $)$; ESI-MS at $\mathrm{m} / 2785.4\left([\mathrm{M}+\mathrm{Na}]^{+}\right)$; HR-ESI-MS (positive-ion mode) at $\mathrm{m} / \mathrm{z} 785.1688[\mathrm{M}+\mathrm{Na}]^{+}$(calcd for 785.6561); $\mathrm{CD}$ (c 0.002, MeOH): $[\theta]_{234}+2527,[\theta]_{255}-1263,[\theta]_{280}+4422$; ${ }^{1} \mathrm{H}$ NMR (acetone- $d_{6}, 300 \mathrm{MHz}$ ): see Table $1 ;{ }^{13} \mathrm{C}$ NMR of the peracetate $7 \mathbf{a}$ (acetone- $\left.d_{6}, 75 \mathrm{MHz}\right) \delta 167.1(\mathrm{CO}, \mathrm{C}-9 ")$, 152.4 (C, C-9), 151.9 (COC, C-7), 150.7 (C, C-5), 144.3 (C, C-3'), 143.6 (C, C-3"), 142.5 (C, C-4"), 142.1 (C, C-4'), 141.0 (C, C-1"), 136.8 (C, C-1'), 135.6 (C, C-5'), 125.8 (CH, C-6”), 124.7 (CH, C-5”), 122.6a (CH, C-6'), 119.9, a, (CH, C-2'), 119.9 (CH, C-2") $)^{\#} 111.1$ (C, C-8), 109.7 (C, C-10), 104.6 (CH, C-6), 77.8 (CH, C-2), 67.1 (CH, C-3), $36.4\left(\mathrm{CH}_{2}, \mathrm{C}-8\right.$ "), 34.7 (CH, C-7"), $26.5\left(\mathrm{CH}_{2}, \mathrm{C}-4\right)$; $\mathrm{a}=$ interchangeable and \# = overlapping. 


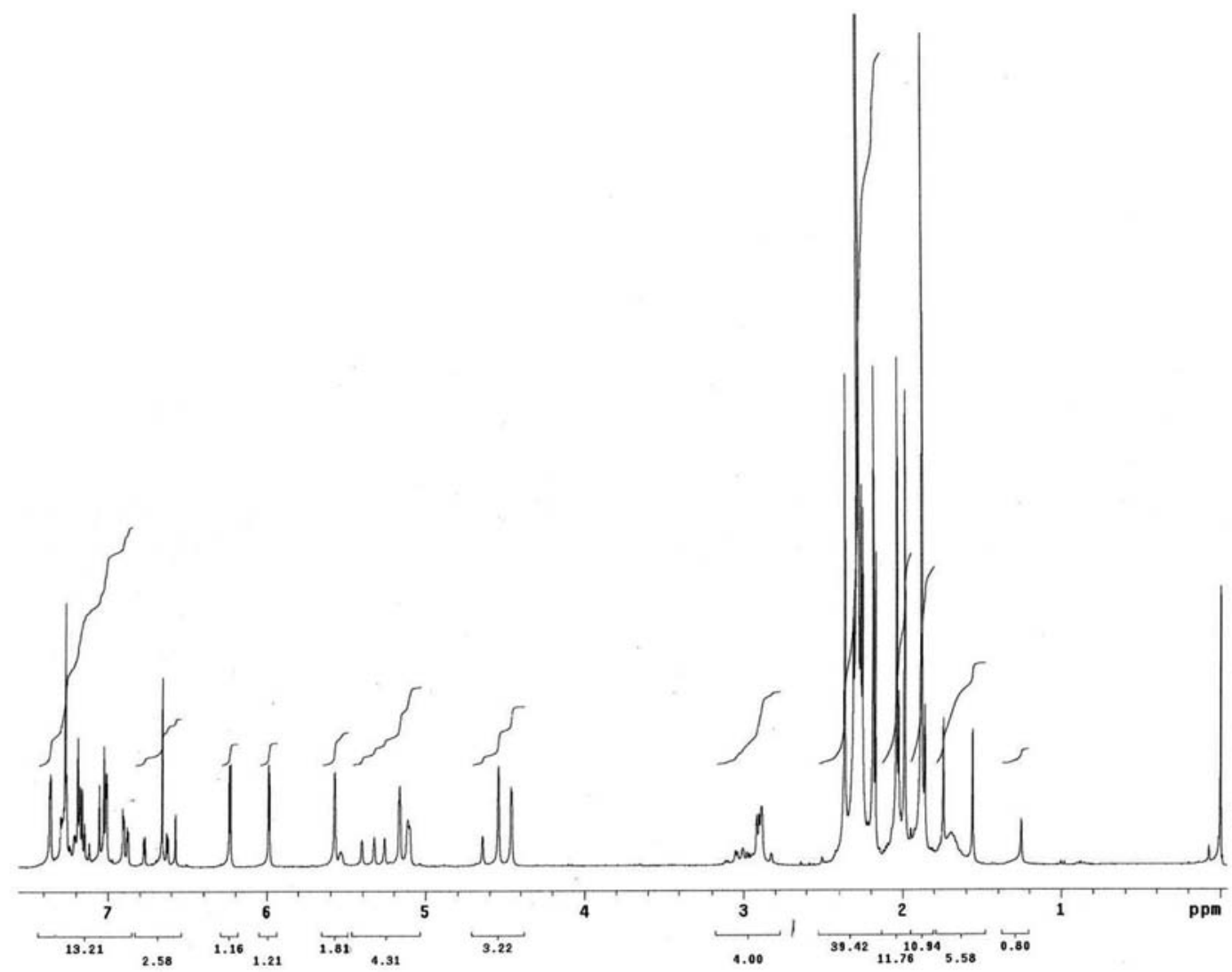

Figure S1. ${ }^{1} \mathrm{H}$ NMR spectrum (300 MHz, $\mathrm{CDCl}_{3}$ ) of epicatechin- $(4 \beta \rightarrow 8)$-epicatechin (PB2).

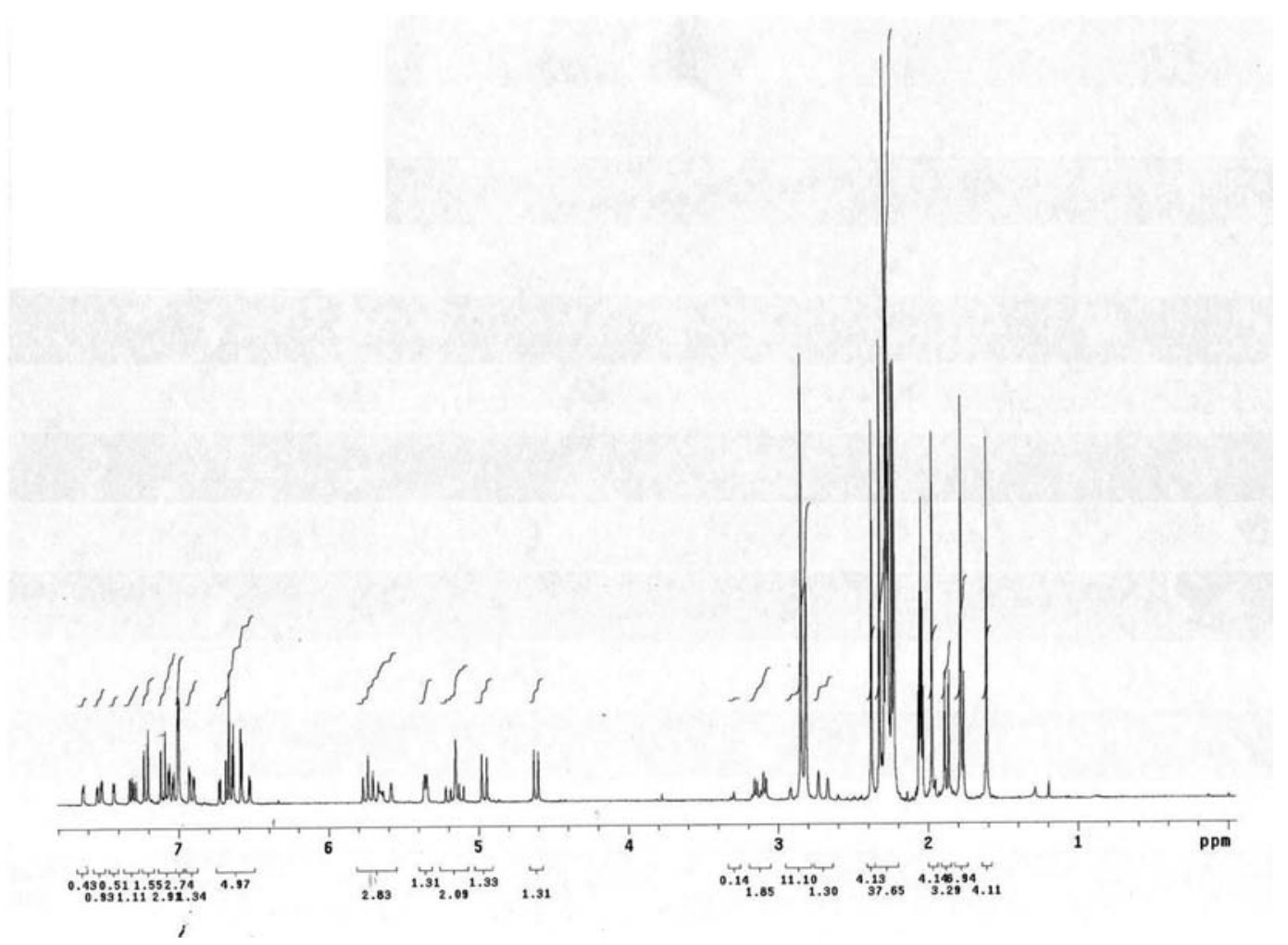

Figure S2. ${ }^{1} \mathrm{H}$ NMR spectrum (300 MHz, acetone- $d_{6}$ ) of catechin-( $\left.4 \alpha \rightarrow 8\right)$-epicatechin (PB4). 


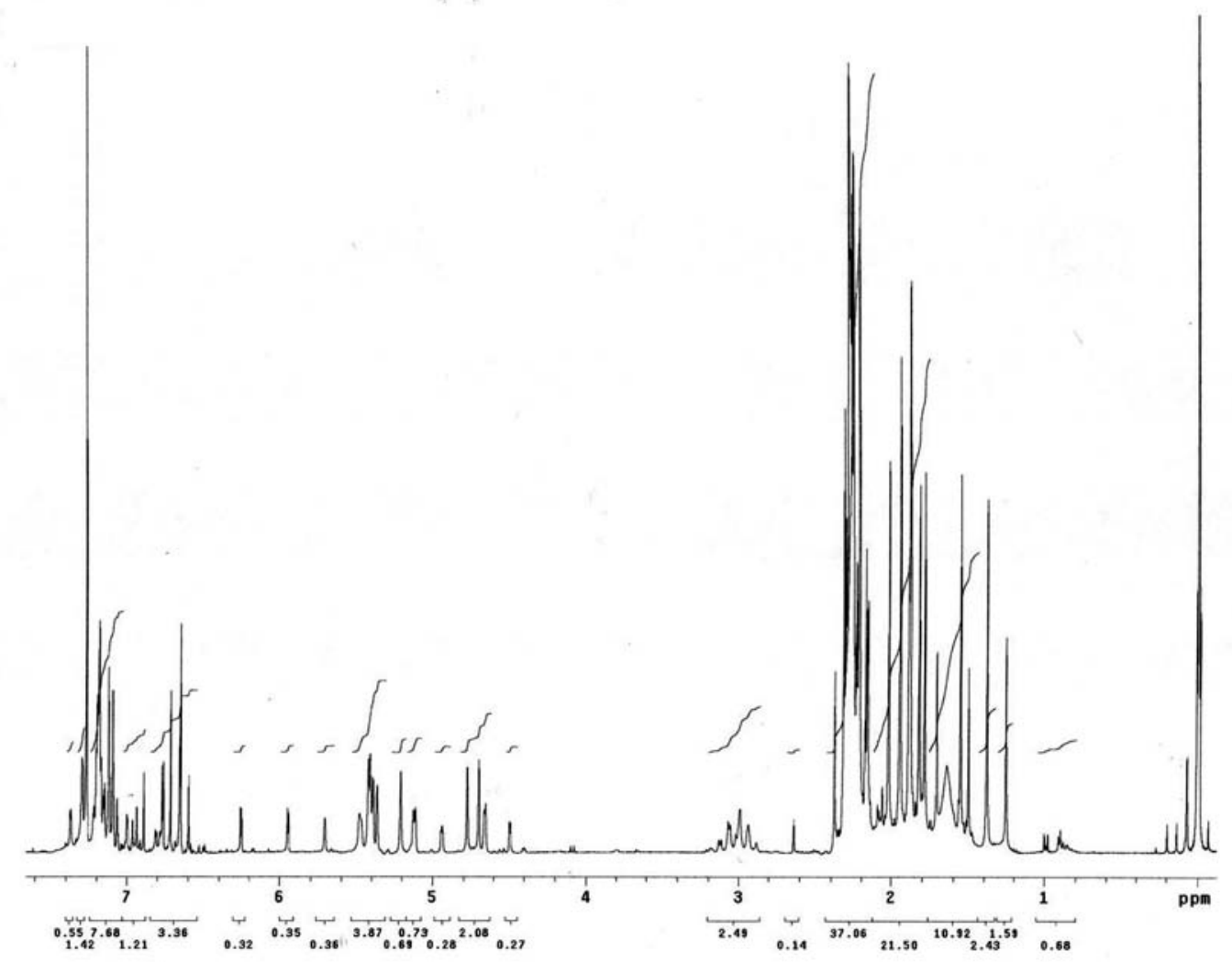

Figure S3. ${ }^{1} \mathrm{H}$ NMR spectrum (300 MHz, $\left.\mathrm{CDCl}_{3}\right)$ of epicatechin- $(4 \beta \rightarrow 8)$-epicatechin-( $\left.4 \beta \rightarrow 8\right)$-epicatechin (PC1).

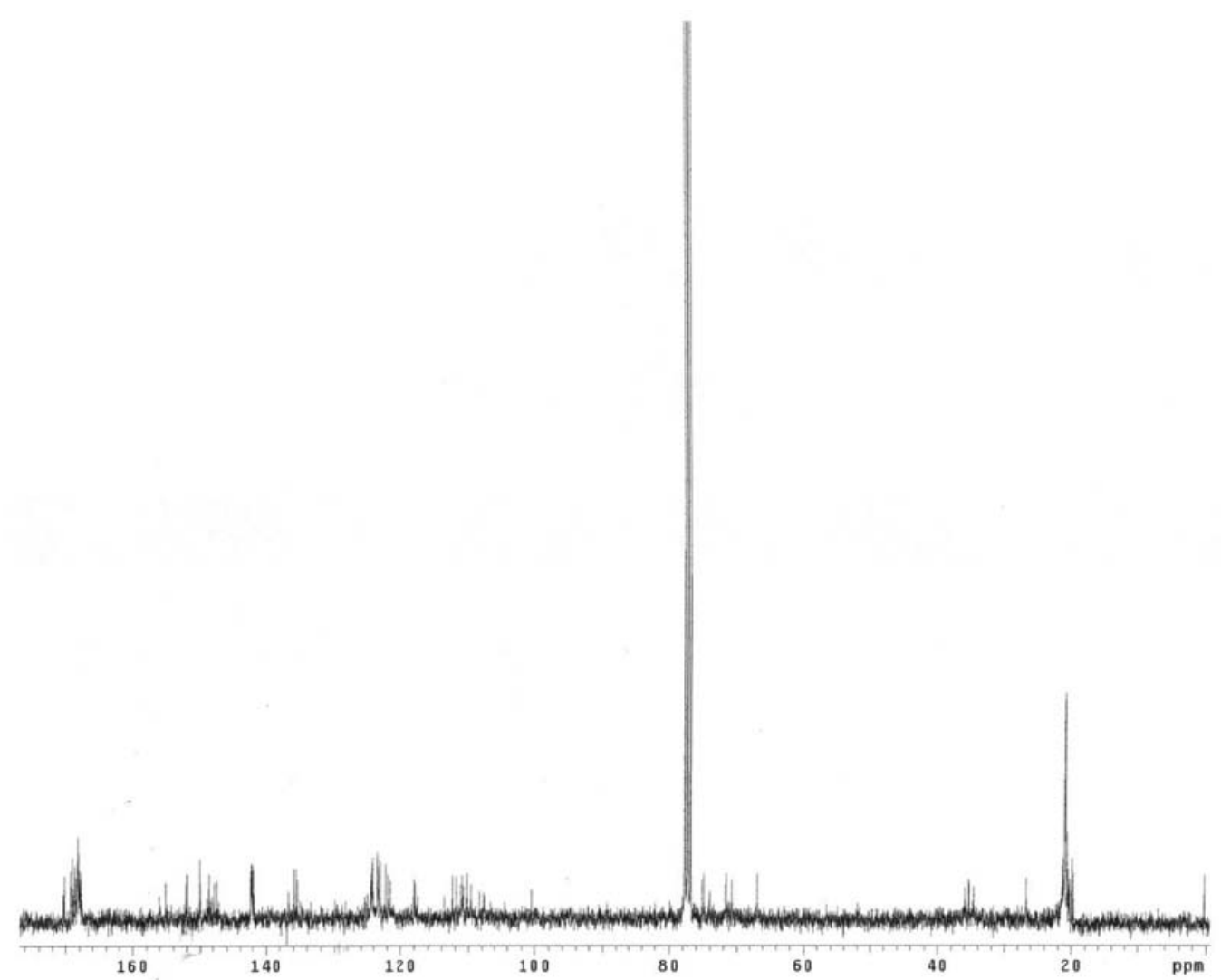

Figure S4. ${ }^{13} \mathrm{C}$ NMR spectrum of epicatechin- $(4 \beta \rightarrow 8)$-epicatechin- $(4 \beta \rightarrow 8)$-epicatechin $(\mathrm{PC} 1)$. 


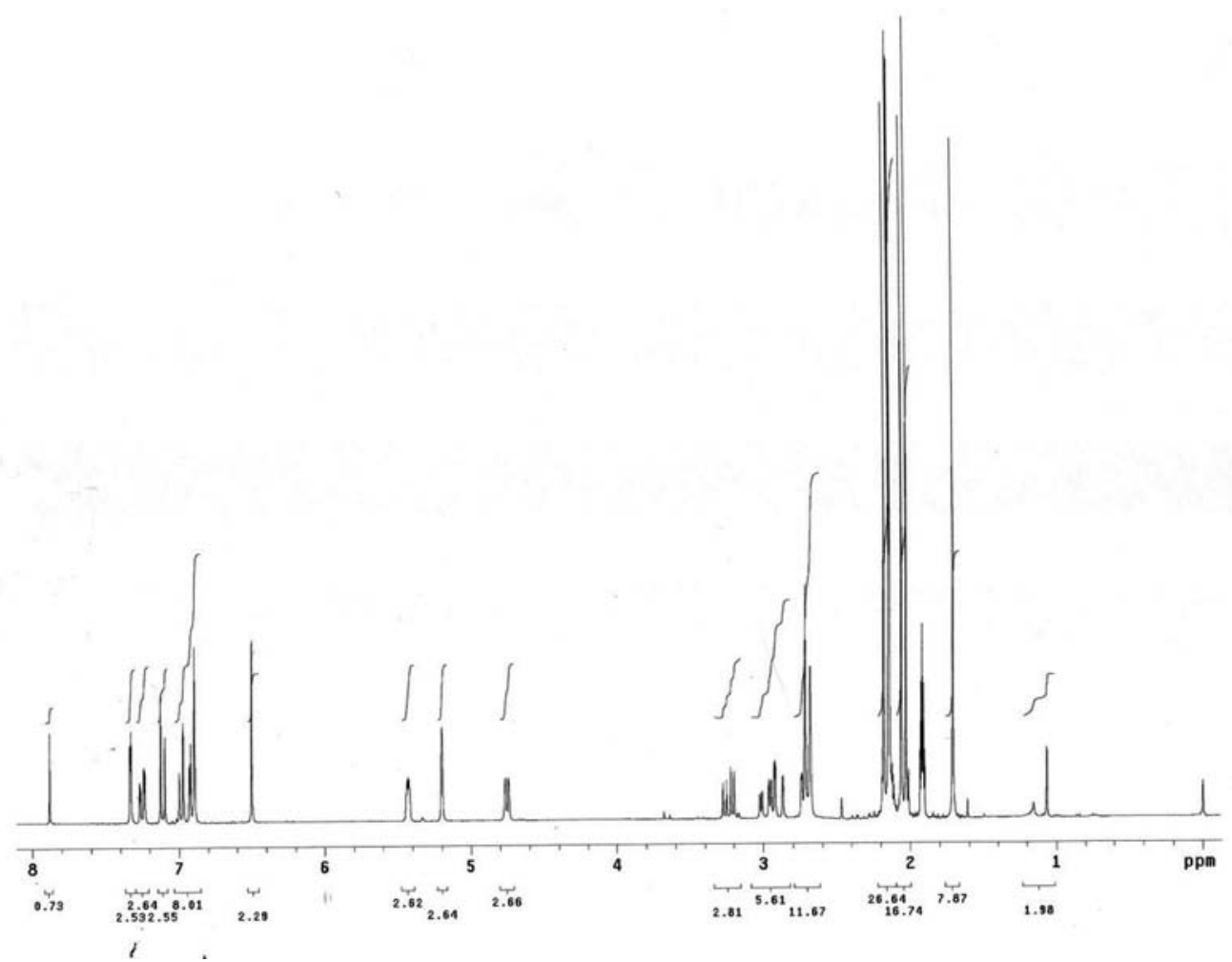

Figure S5. ${ }^{1} \mathrm{H}$ NMR spectrum ( $300 \mathrm{MHz}$, acetone- $d_{6}$ ) of cinchonain Ia.

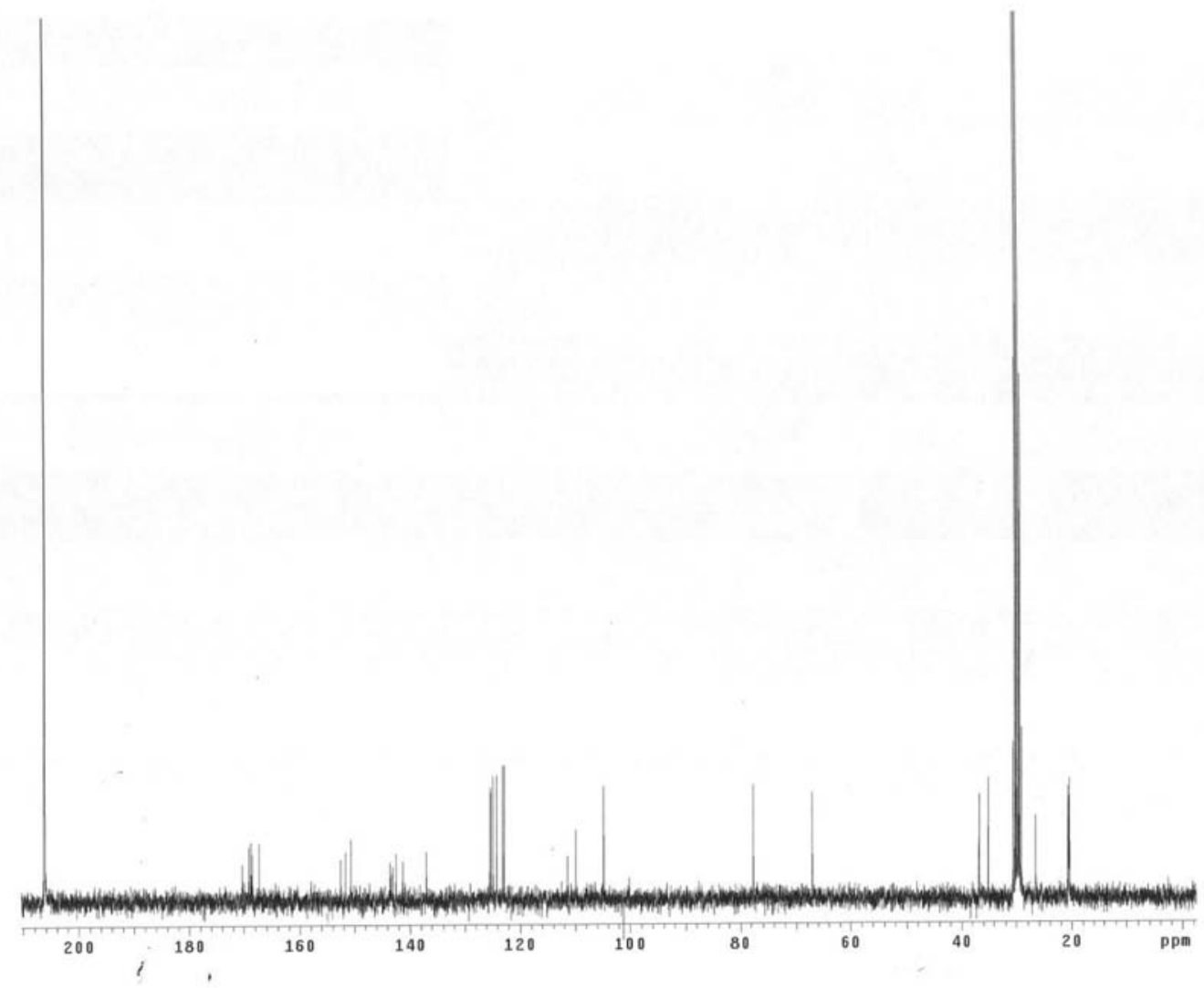

Figure S6. ${ }^{13} \mathrm{C}$ NMR spectrum of cinchonain Ia. 


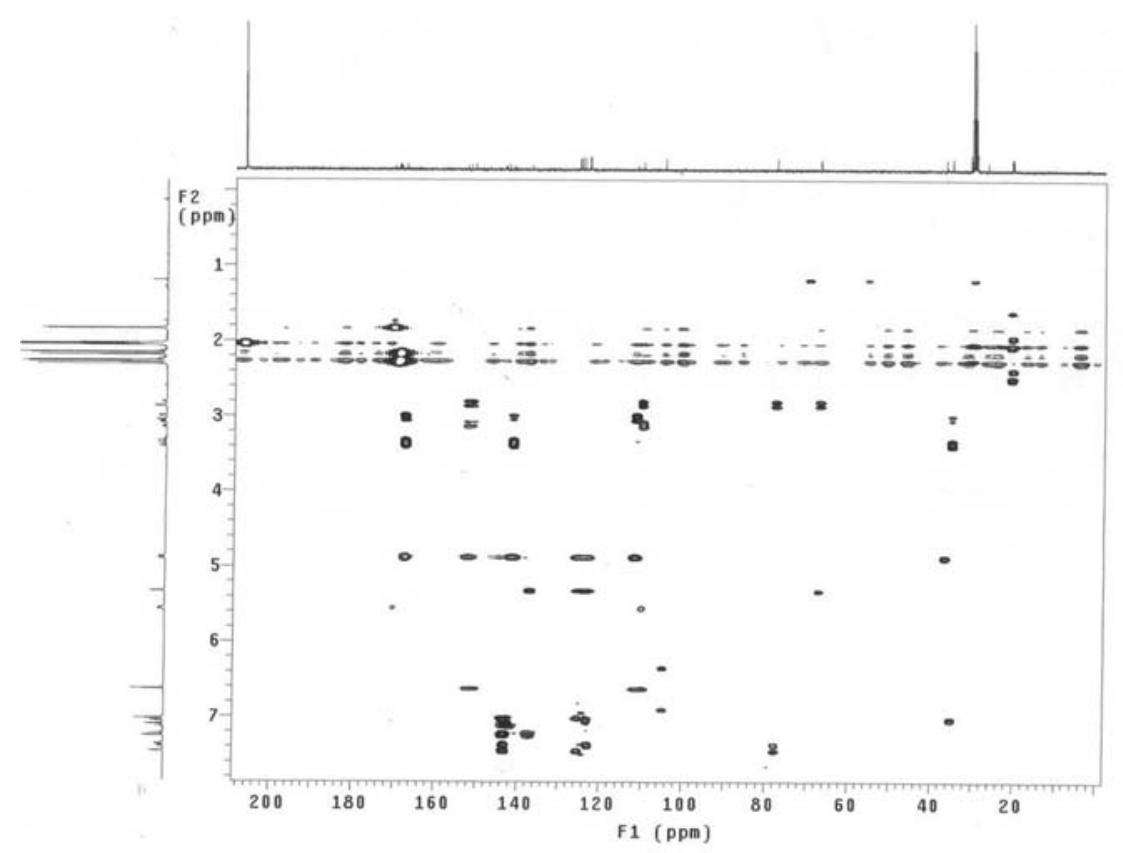

Figure S7. HMBC NMR spectrum of cinchonain Ia.

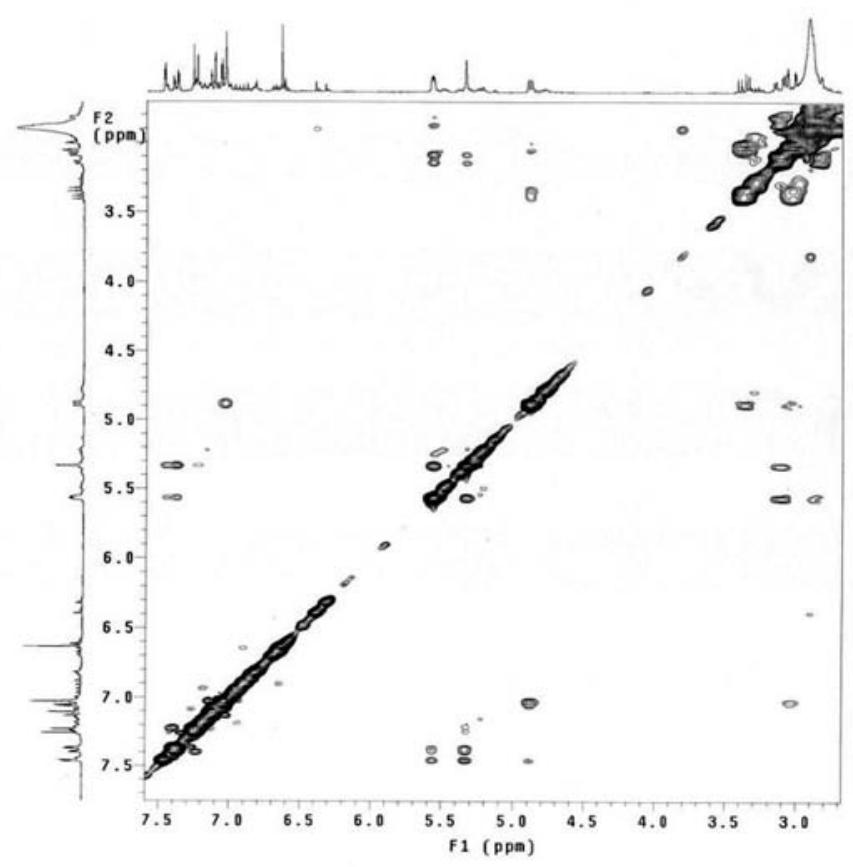

Figure S8. NOESY NMR spectrum of cinchonain Ia. 


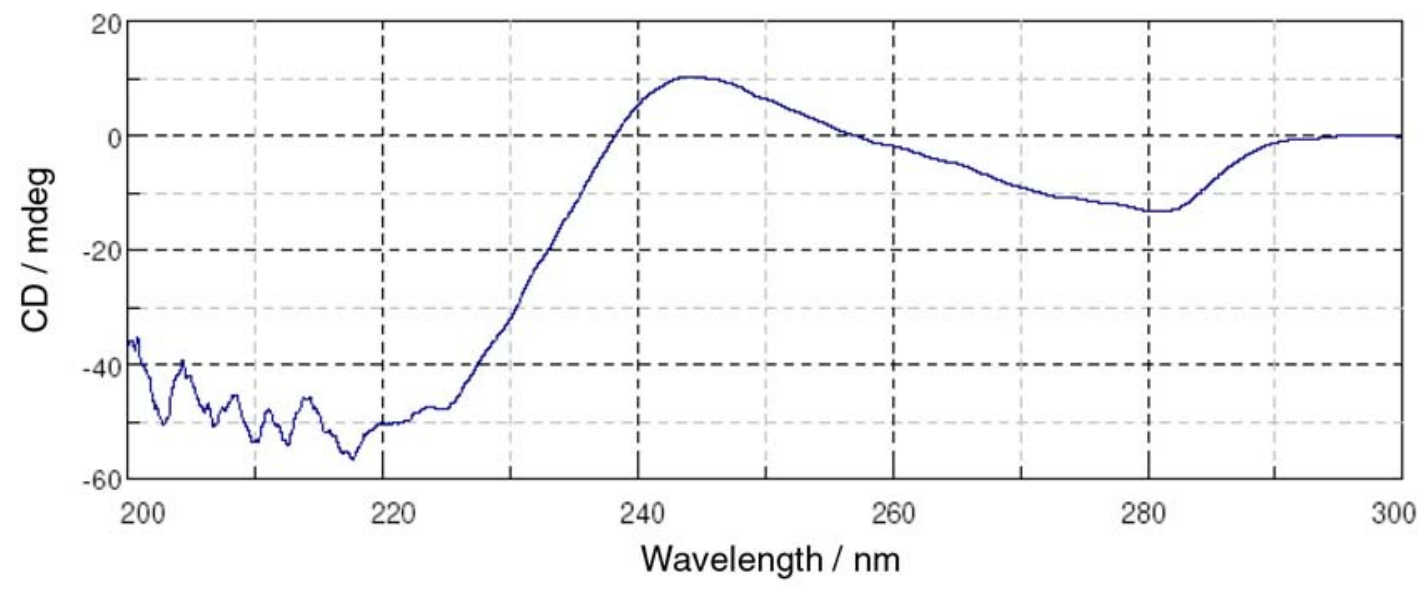

Figure S9. Circular dichroism spectrum of cinchonain $\mathrm{Ia}(\mathrm{MeOH} ; \mathrm{c}=0,1)$.

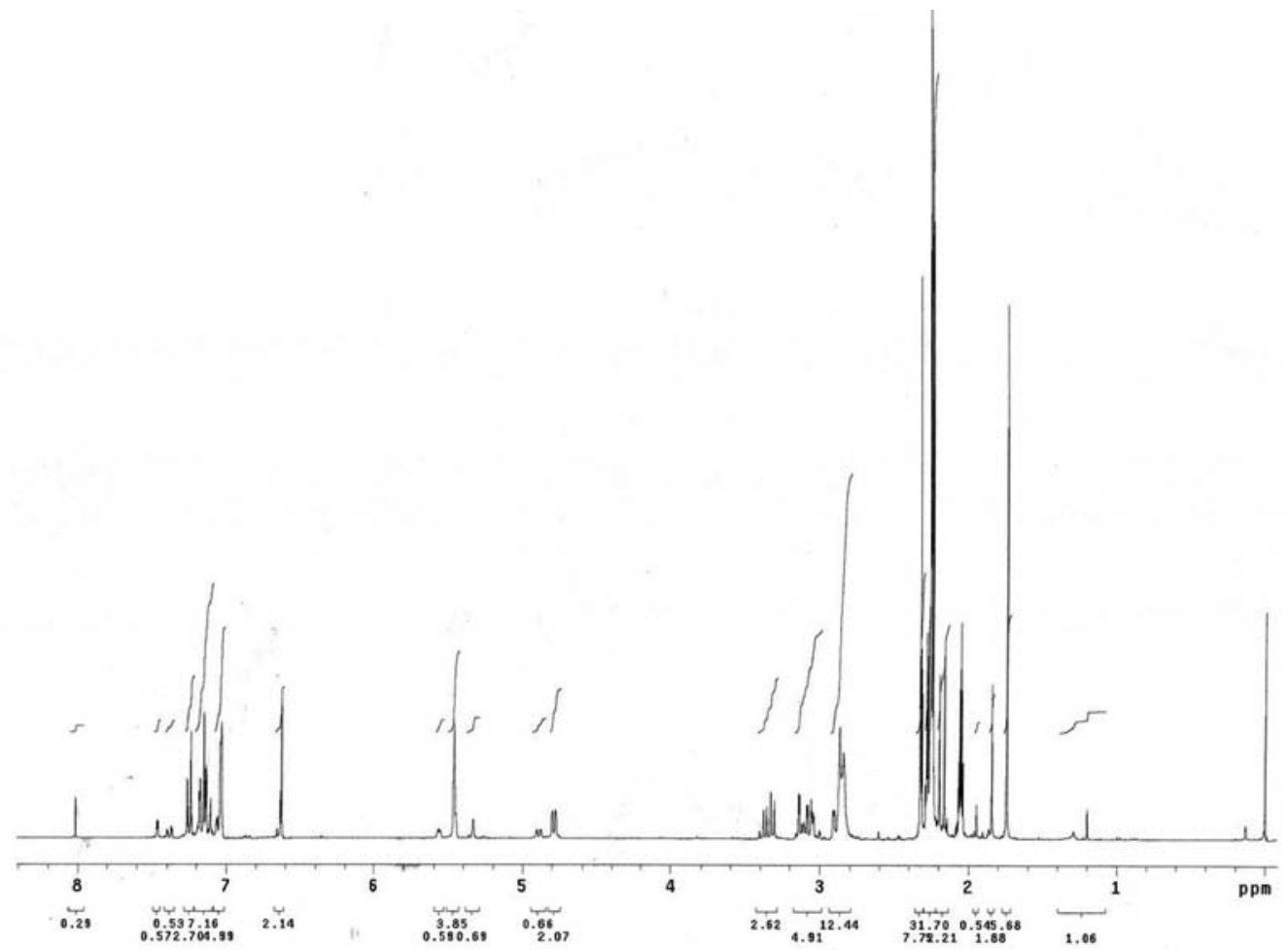

Figure S10. ${ }^{1} \mathrm{H}$ NMR spectrum (300 MHz, acetone- $\left.d_{6}\right)$ of cinchonain Ib. 


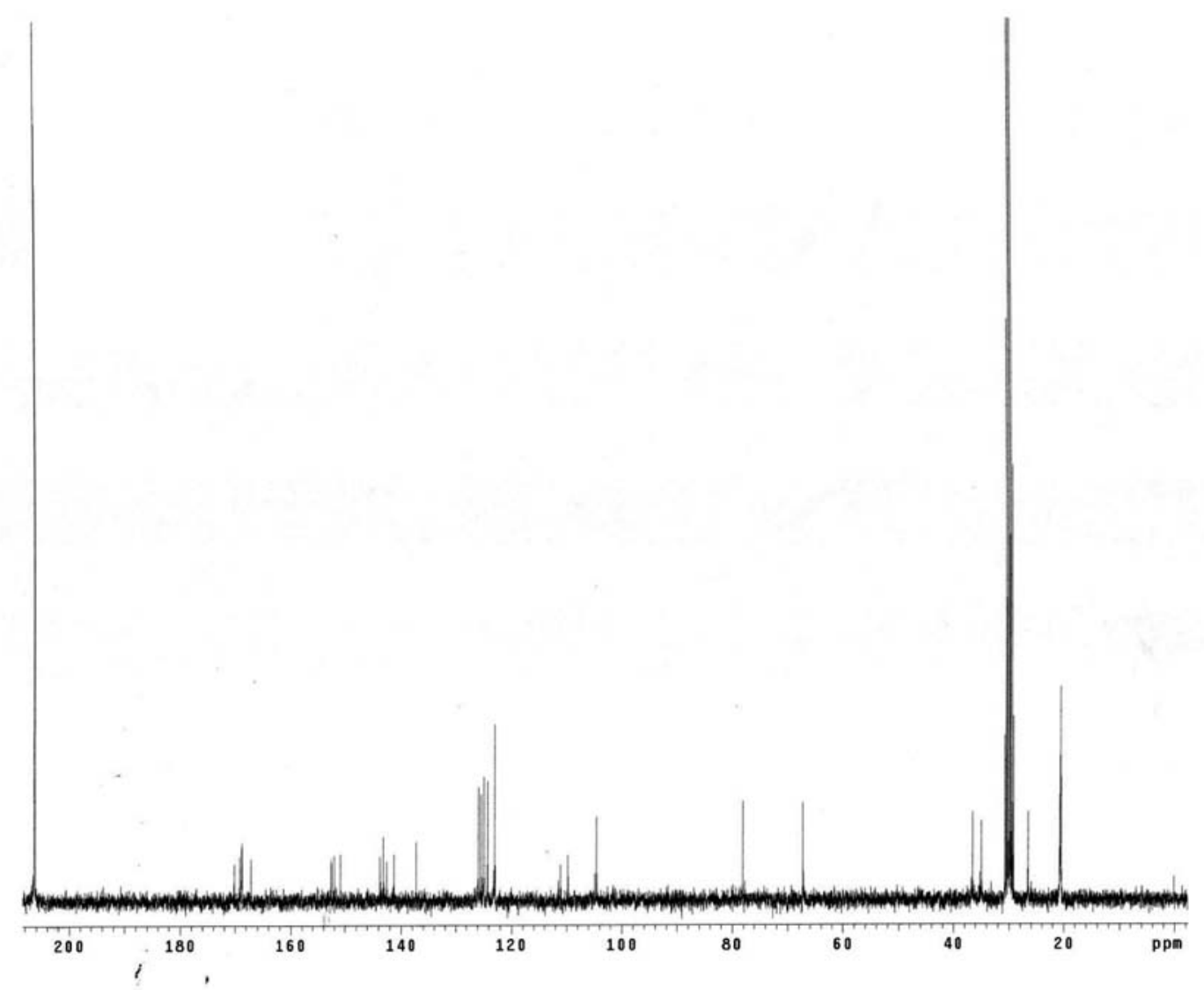

Figure S11. ${ }^{13} \mathrm{C}$ NMR spectrum of cinchonain Ib.

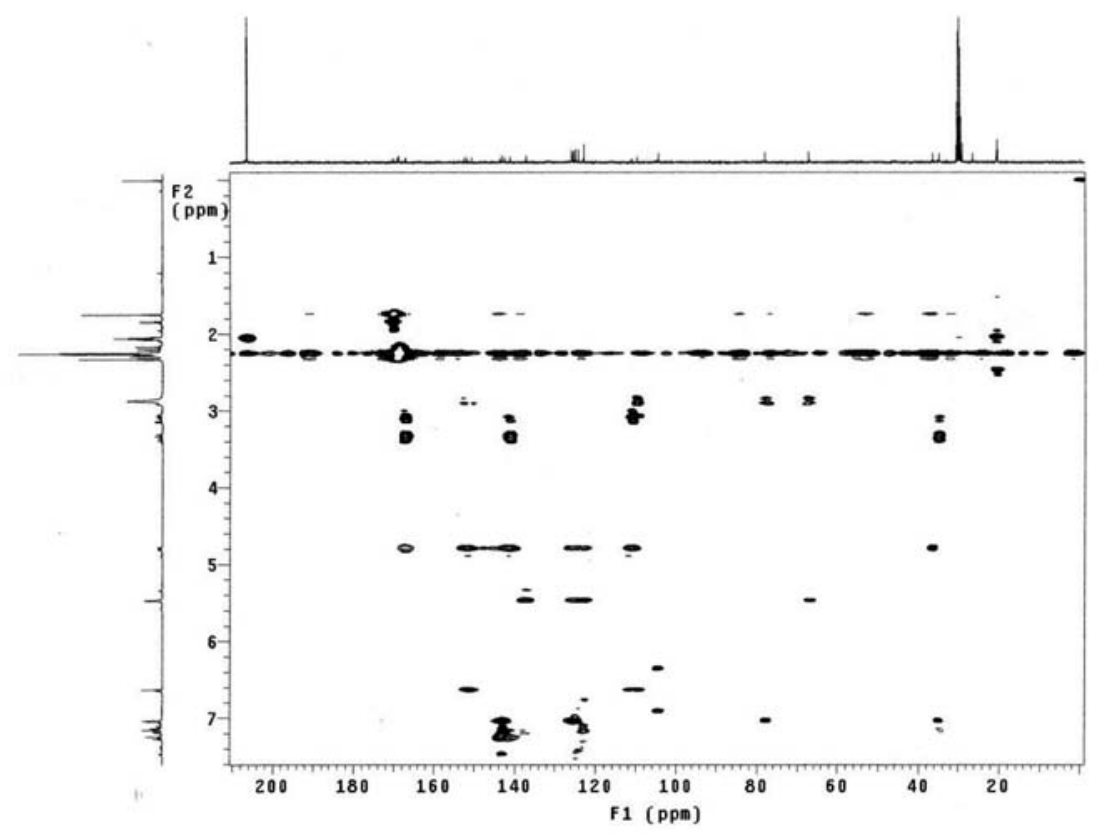

Figure S12. HMBC NMR spectrum of cinchonain Ib. 


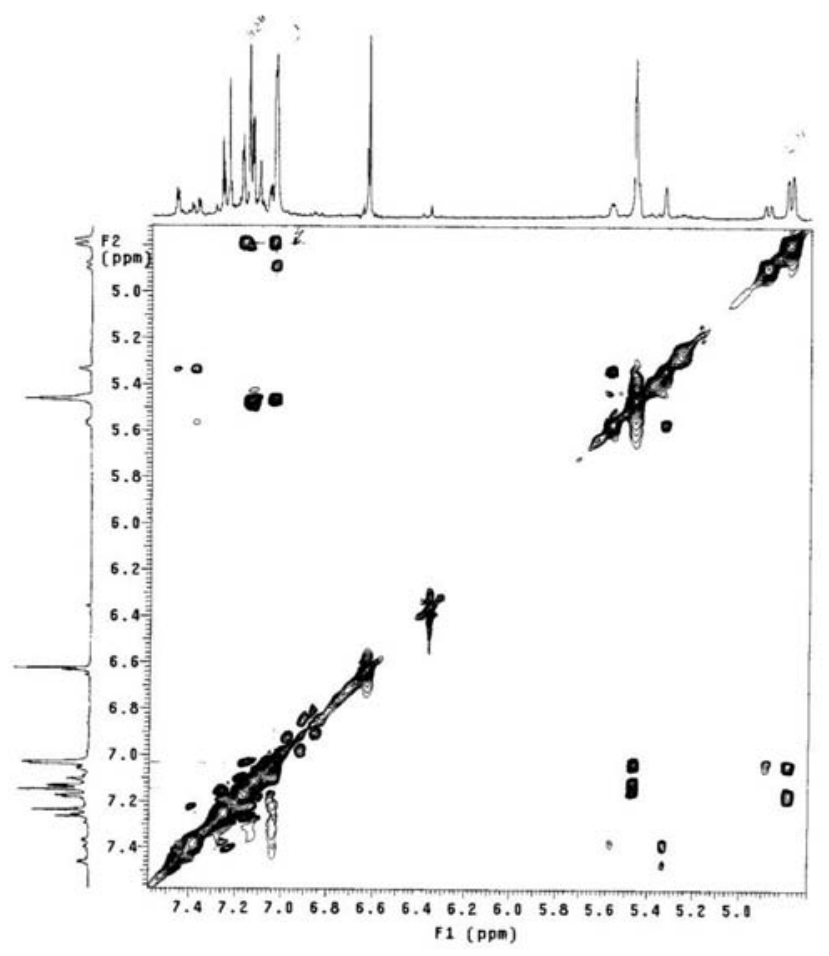

Figure S13. NOESY NMR spectrum of cinchonain Ib.

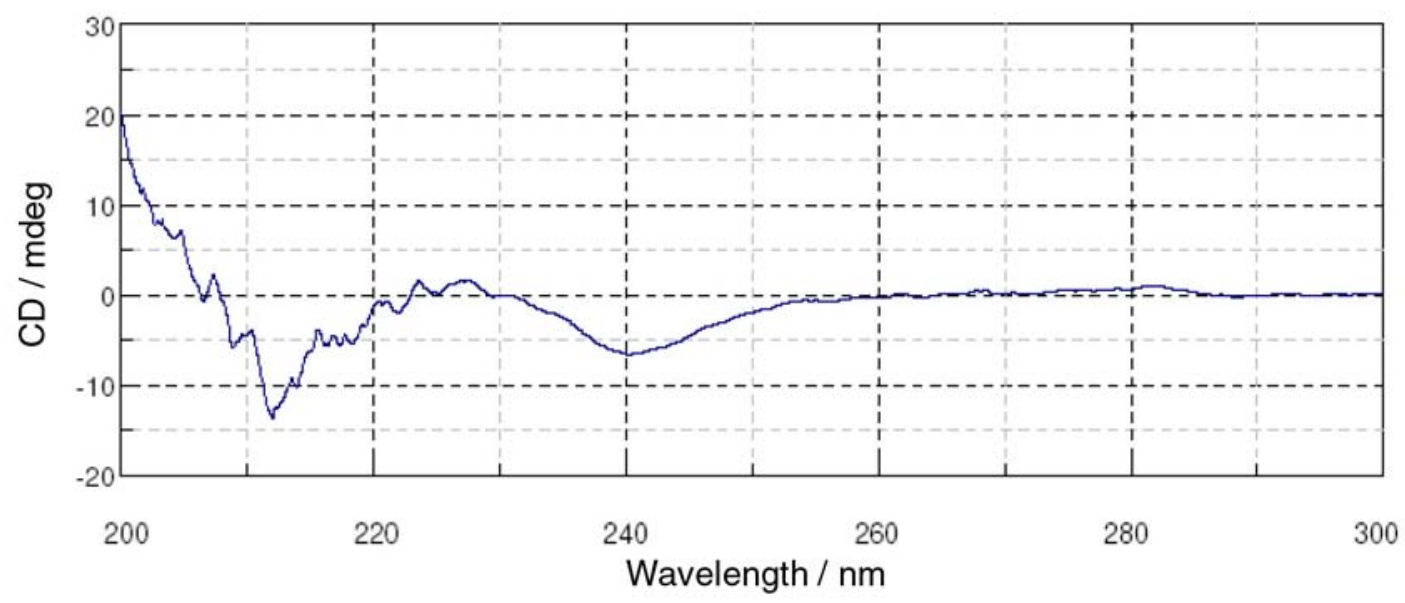

Figure S14. Circular dichroism spectrum of cinchonain $\mathrm{Ib}(\mathrm{MeOH} ; \mathrm{c}=0,1)$. 


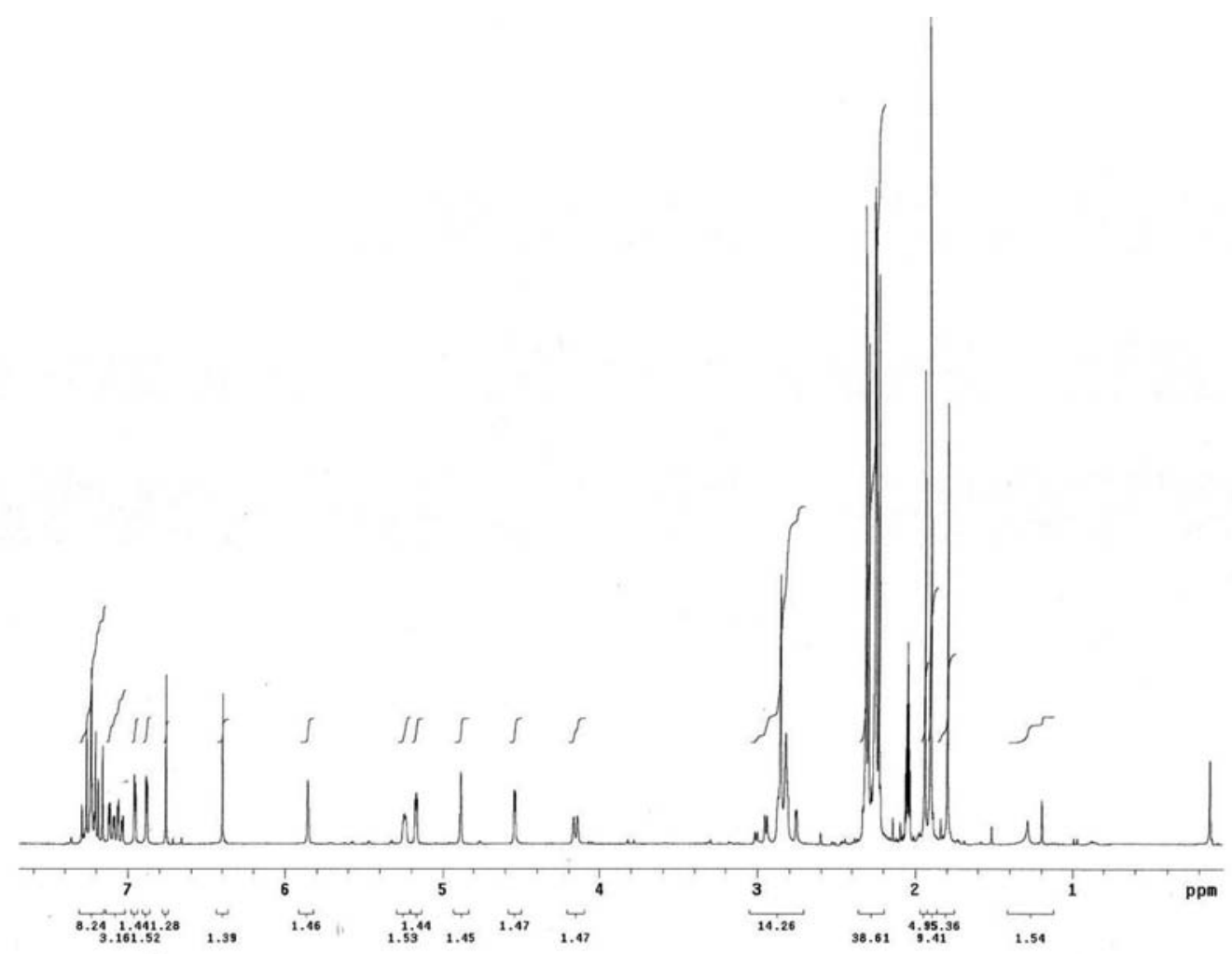

Figure S15. ${ }^{1} \mathrm{H}$ NMR spectrum ( $300 \mathrm{MHz}$, acetone- $d_{6}$ ) of cinchonain IIb.

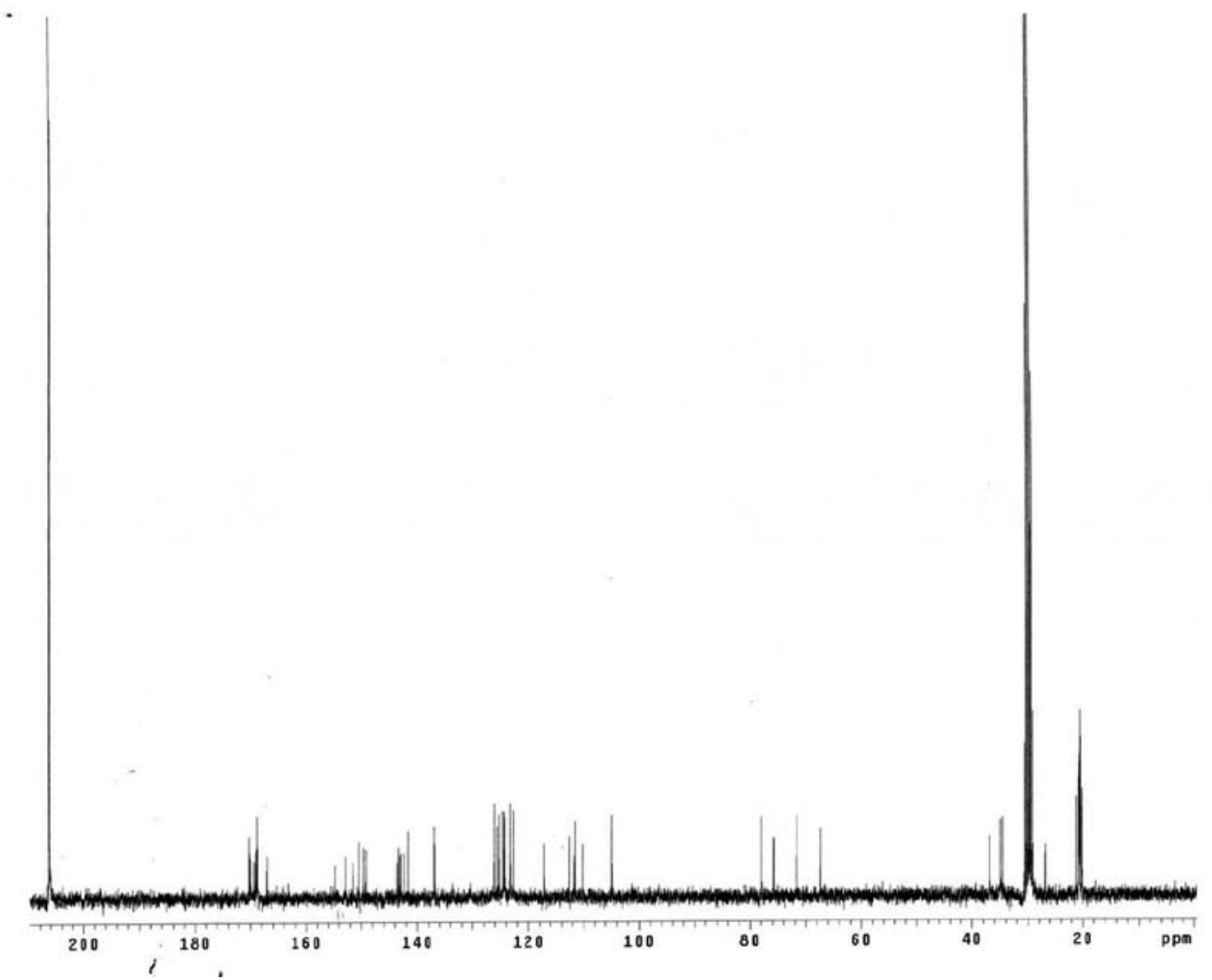

Figure S16. ${ }^{13} \mathrm{C}$ NMR spectrum of cinchonain IIb. 


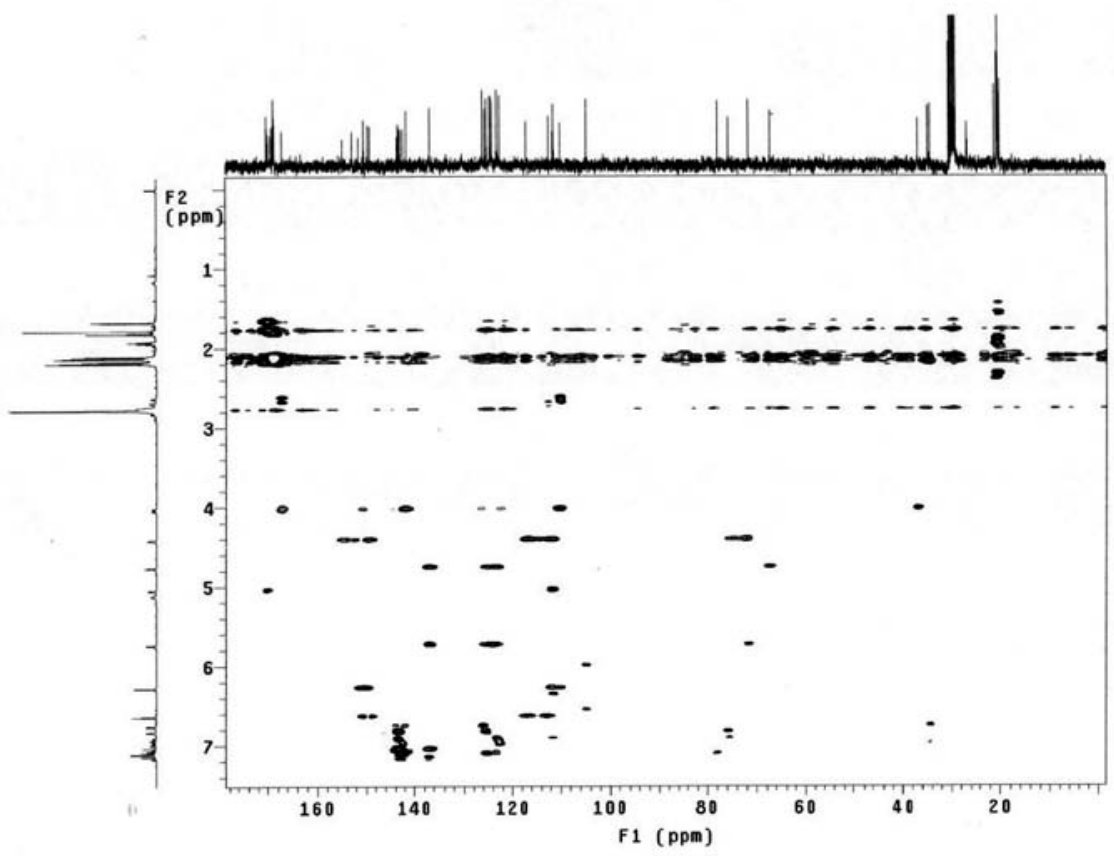

Figure S17. HMBC NMR spectrum of cinchonain IIb.

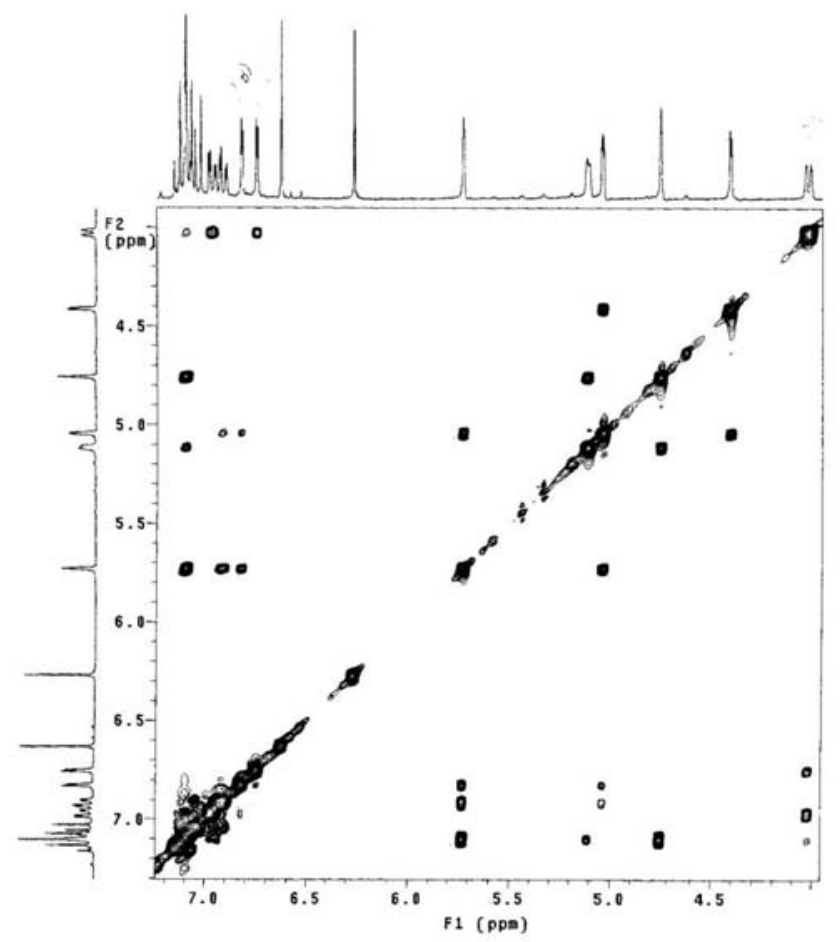

Figure S18. NOESY NMR spectrum of cinchonain IIb. 


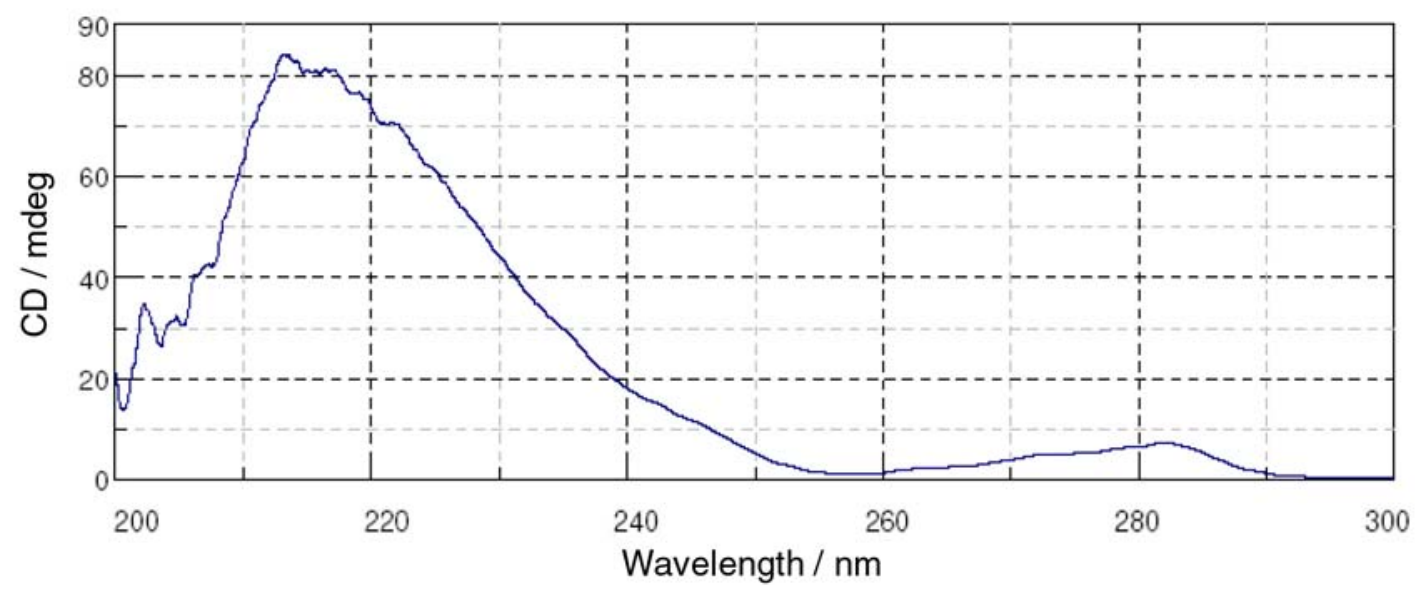

Figure S19. Circular dichroism spectrum of cinchonain $\mathrm{IIb}(\mathrm{MeOH} ; \mathrm{c}=0,1)$.

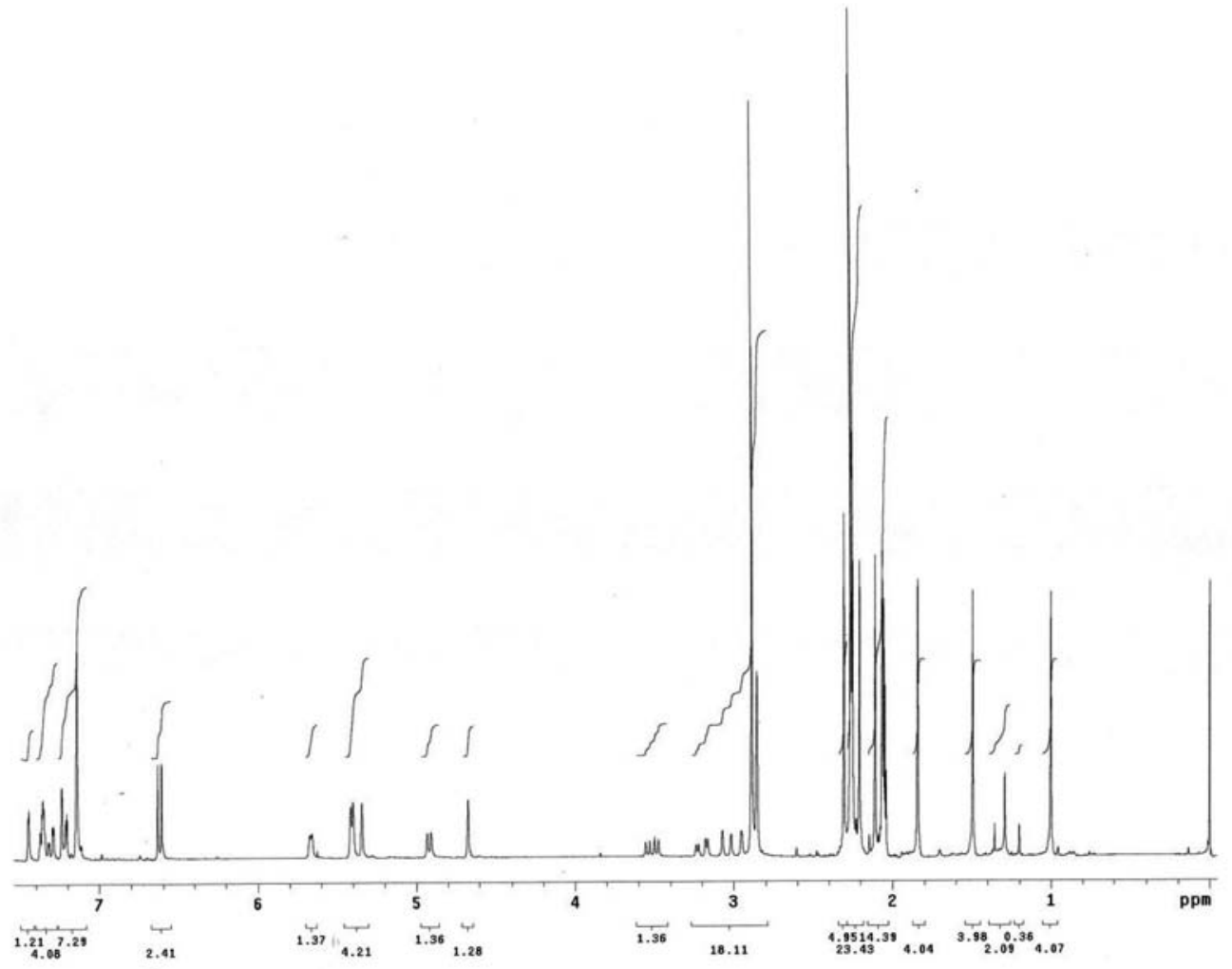

Figure S20. ${ }^{1} \mathrm{H}$ NMR spectrum $\left(300 \mathrm{MHz}\right.$, acetone- $d_{6}$ ) of cinchonain IIa. 


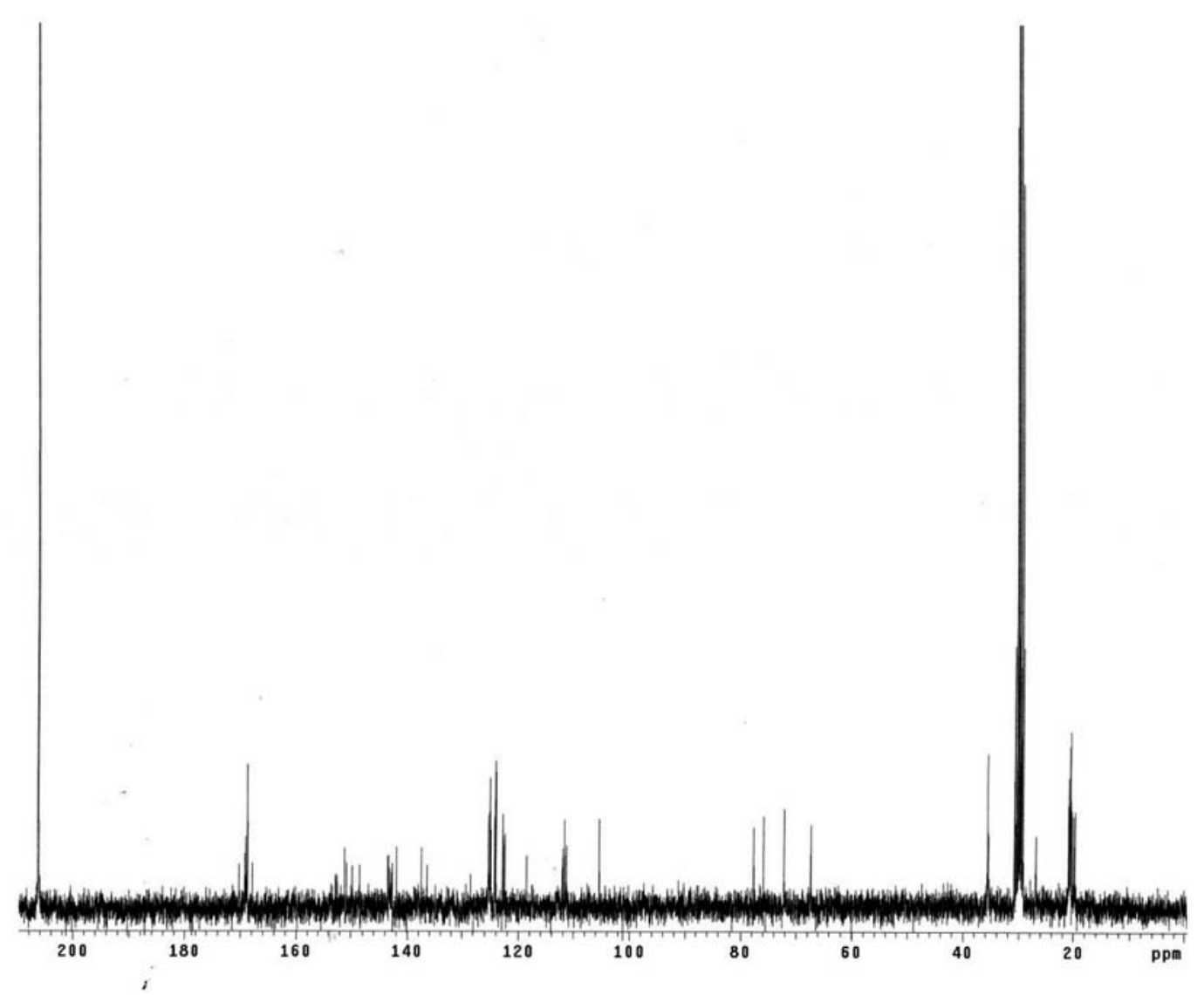

Figure S21. ${ }^{13} \mathrm{C}$ NMR spectrum of cinchonain IIa.

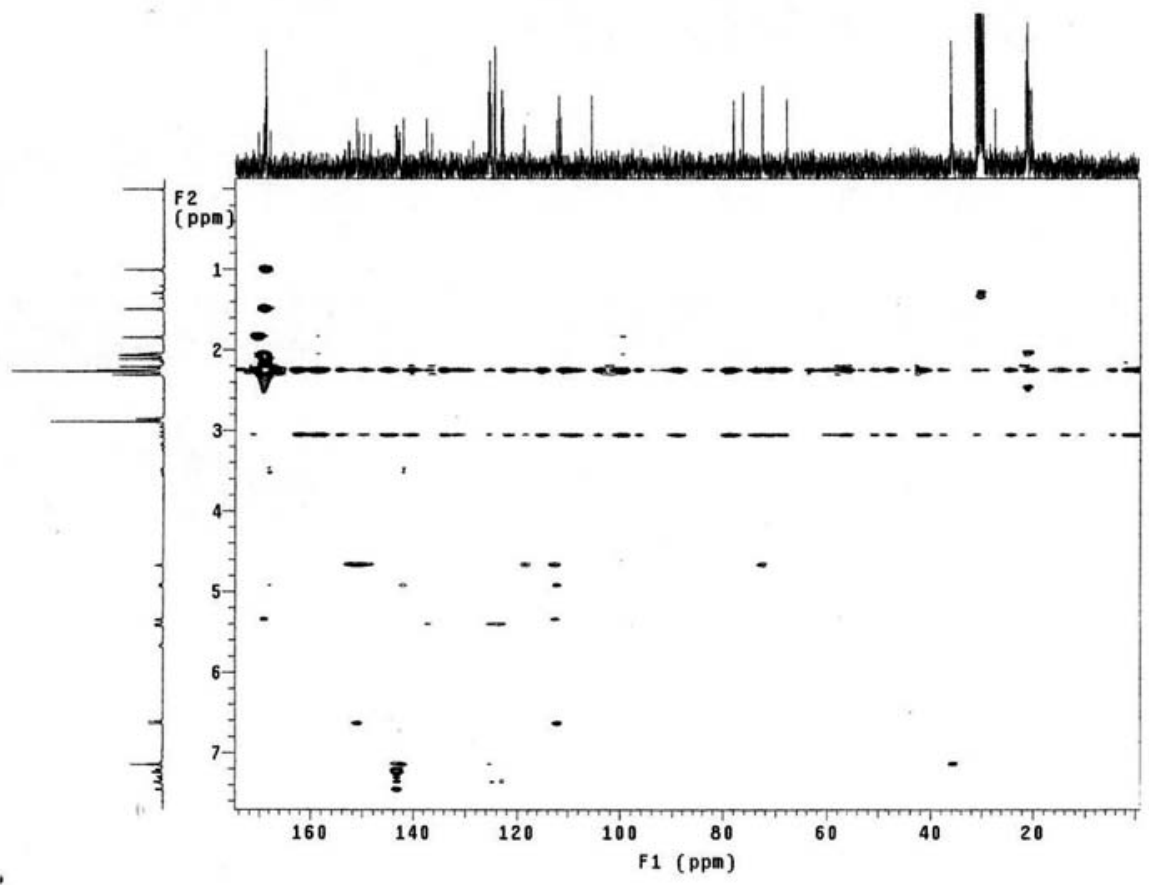

Figure S22. HMBC NMR spectrum of cinchonain IIa. 


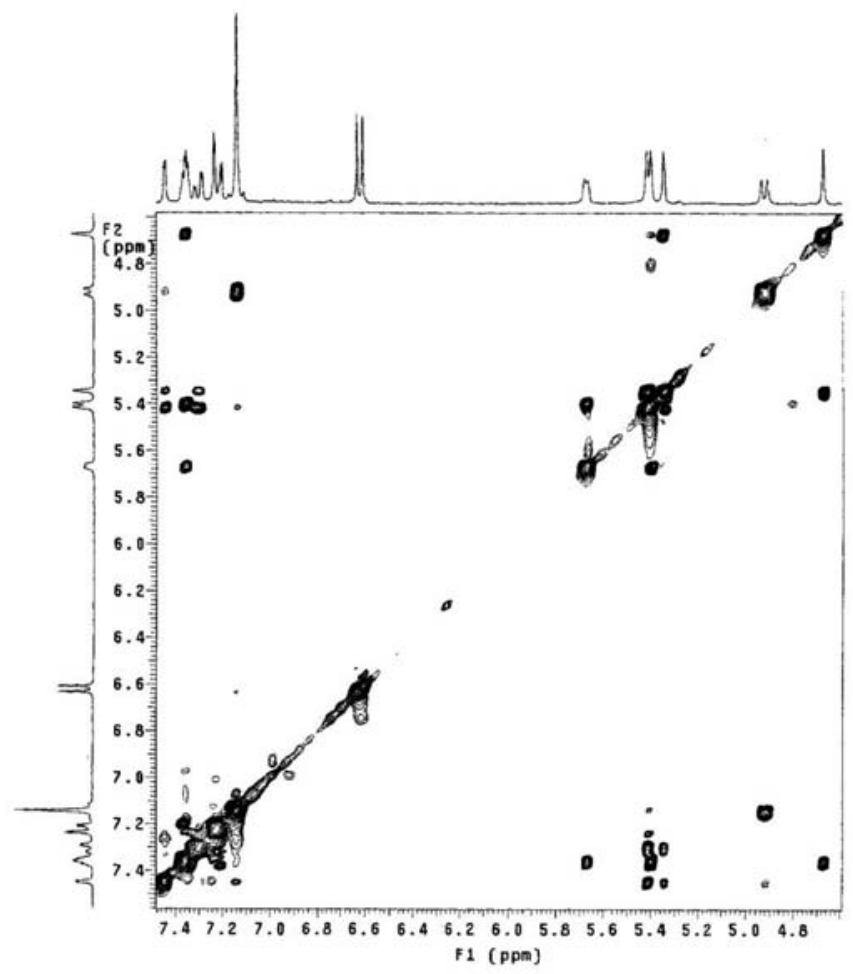

Figure S23. NOESY NMR spectrum of cinchonain IIa.

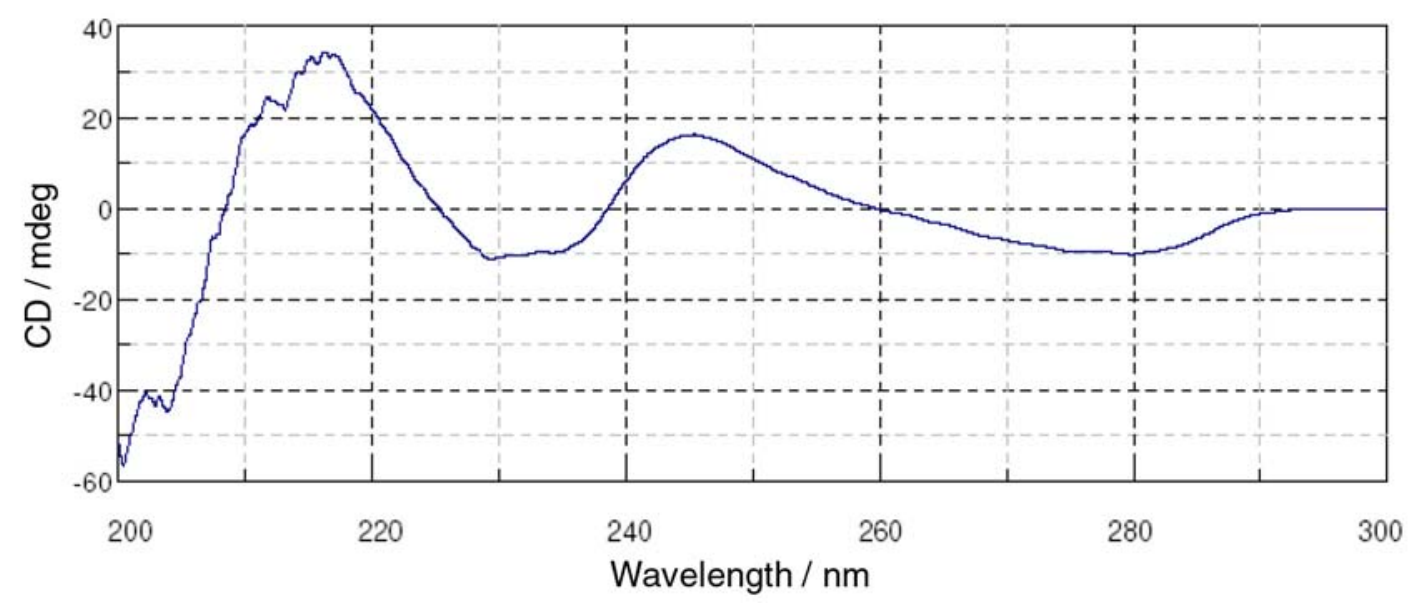

Figure S24. Circular dichroism spectrum of cinchonain IIa $(\mathrm{MeOH} ; \mathrm{c}=0,1)$. 


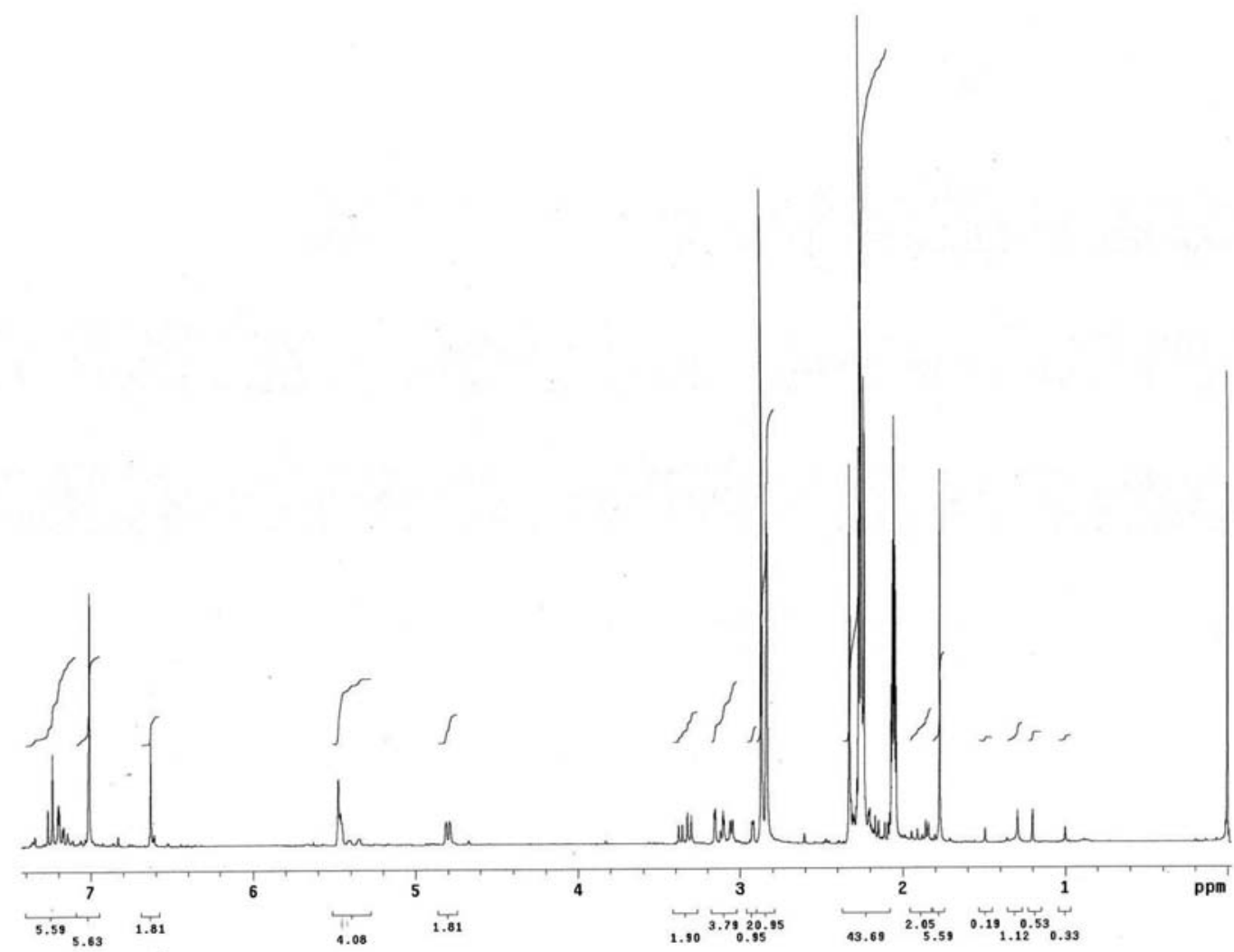

Figure S25. ${ }^{1} \mathrm{H}$ NMR spectrum $\left(300 \mathrm{MHz}\right.$, acetone- $\left.d_{6}\right)$ of apocynin E.

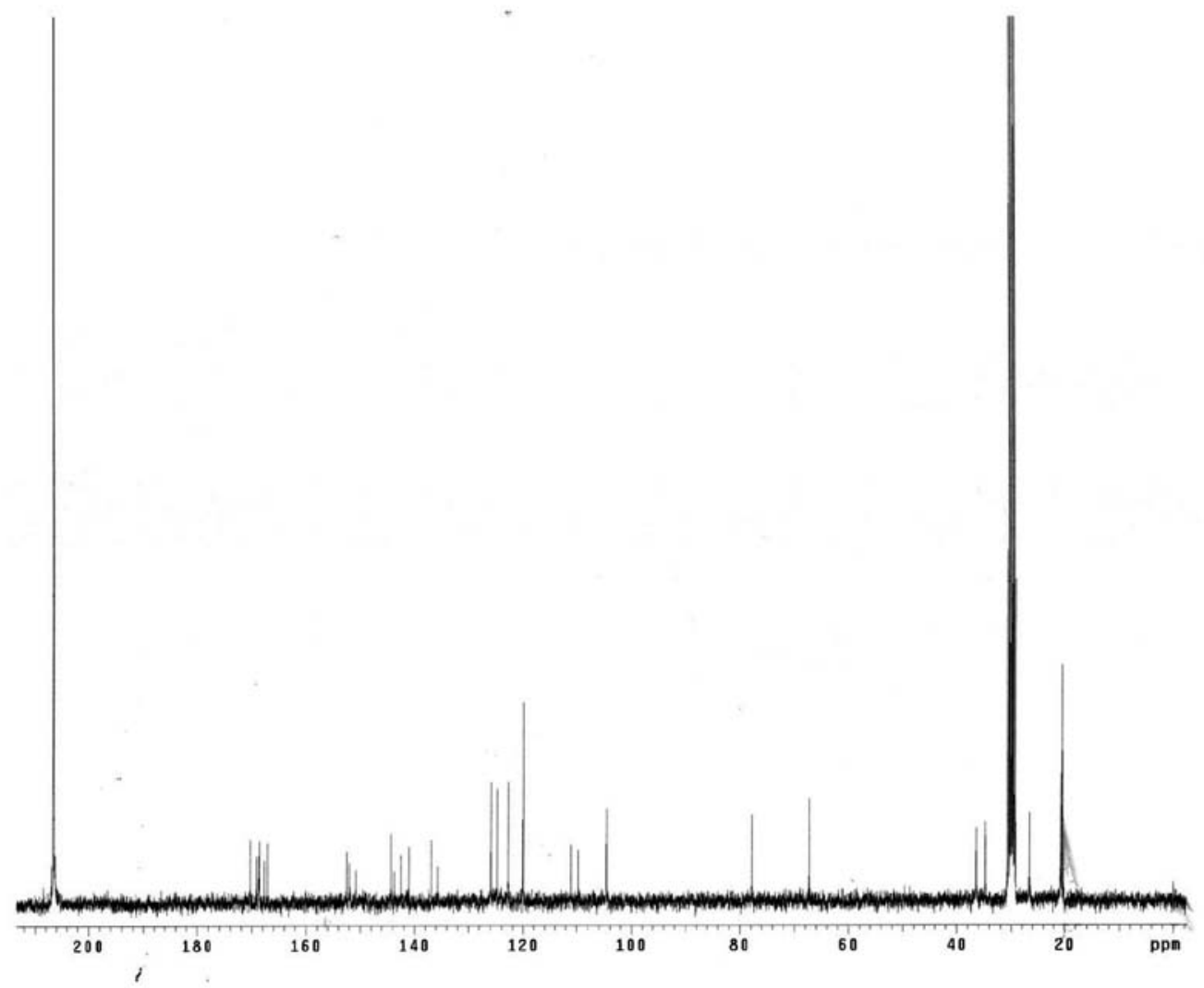

Figure S26. ${ }^{13} \mathrm{C}$ NMR spectrum of apocynin E. 
Vol. 22, No. 11, 2011

Resende et al.

$\mathrm{S} 17$

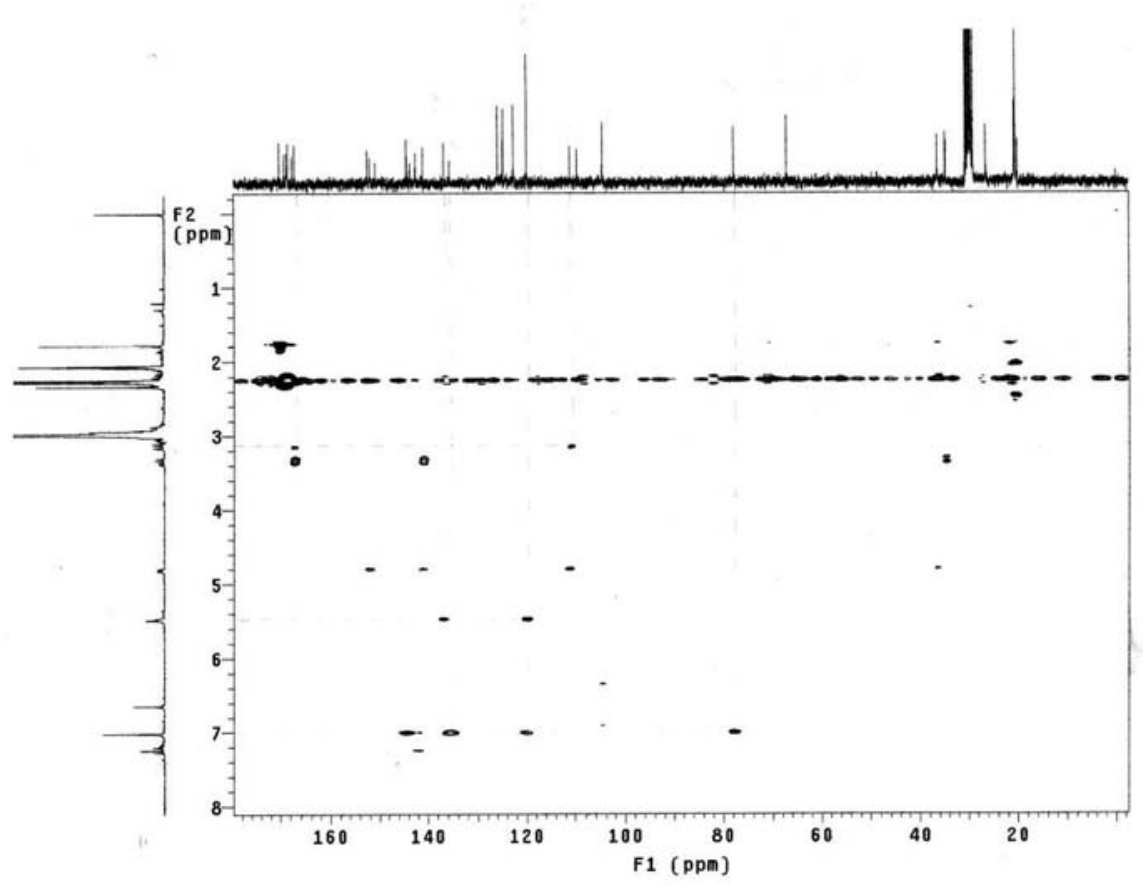

Figure S27. HMBC NMR spectrum of apocynin E.

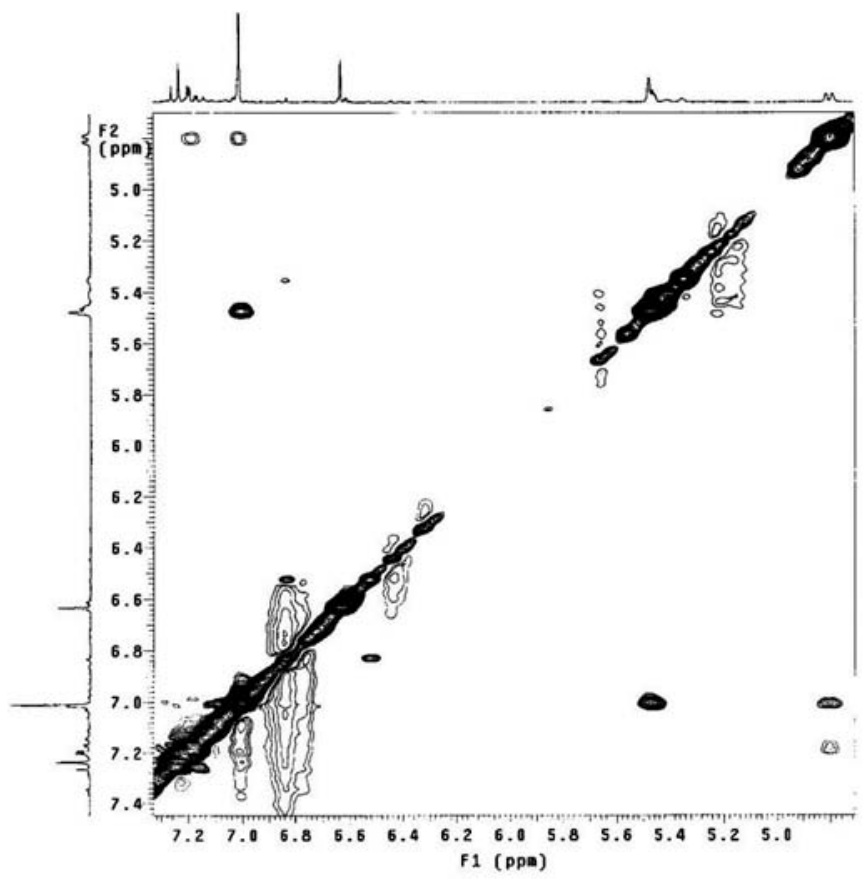

Figure S28. NOESY NMR spectrum of apocynin E. 


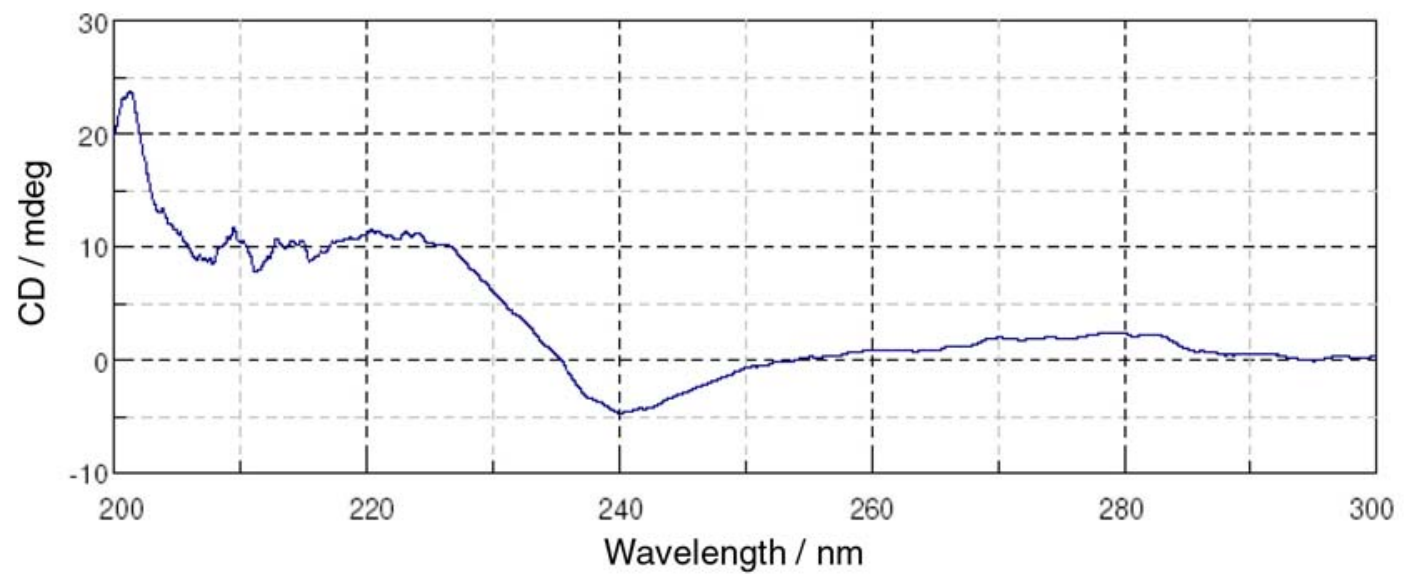

Figure S29. Circular dichroism spectrum of apocynin $\mathrm{E}(\mathrm{MeOH} ; \mathrm{c}=0,1)$. 